Check for updates

Cite this: RSC Adv., 2019, 9, 3443

Received 23rd October 2018

Accepted 3rd January 2019

DOI: $10.1039 / c 8 r a 08762 h$

rsc.li/rsc-advances

\section{Copper nanoparticles anchored onto boron-doped graphene nanosheets for use as a high performance asymmetric solid-state supercapacitor $\dagger$}

\author{
P. Muthu Pandian and A. Pandurangan (iD *
}

There is a high demand for high energy and power density in the field of energy storage devices. To rectify these limitations, a novel asymmetric solid-state supercapacitor (ASSC) was designed and fabricated using a copper anchored boron doped graphene nanosheet (CuBG) as a negative electrode and reduced graphene nanoplatelets as a positive electrode with $\mathrm{H}_{2} \mathrm{SO}_{4} / P V A$ as the quasi-solid electrolyte. The CuBG was prepared using a two step hydrothermal process followed by pyrolysis at different temperatures using chemical vapour deposition (CVD), using copper sulphate $\left(\mathrm{CuSO}_{4}\right)$ and boron-trioxide $\left(\mathrm{B}_{2} \mathrm{O}_{3}\right)$ as precursors, for doping in graphene oxide. Owing to the remarkable structure and morphology of $\mathrm{Cu}$ nanoparticles on nanosheets of boron intercalated with graphene oxide, the nanosheets exhibit a high specific capacitance of $483 \mathrm{Fg}^{-1}$ at $1 \mathrm{Ag}^{-1}$ with a capacitance retention of $96 \%$ after 5000 cycles, respectively, in a two-electrode system. In addition, the designed and fabricated solid state ASSC device of rGO//CuBG exhibited a high energy and power density of $132.5 \mathrm{~W} \mathrm{~h} \mathrm{~kg}^{-1}$ and $1000 \mathrm{~W} \mathrm{~kg}^{-1}$, respectively, in a wide potential window of $2.0 \mathrm{~V}$, with an excellent stability, retaining $91 \%$ of its initial specific capacitance after 5000 cycles. The electrochemical capacitance of CuBG was also evaluated in a three and two electrode system using a $\mathrm{KOH}$ and $\mathrm{KOH} / \mathrm{PVA}$ solid electrolyte respectively. A specific capacitance of $87.5 \mathrm{Fg}^{-1}$ was achieved at $1 \mathrm{Ag}^{-1}$ using the fabricated asymmetric device with a $31.1 \mathrm{~W} \mathrm{~h} \mathrm{~kg}^{-1}$ energy density at a corresponding power density of $800 \mathrm{~W} \mathrm{~kg}^{-1}$ and an $85 \%$ capacitance was retained after 5000 cycles. The kinetics of the interfacial charge transport phenomena were analysed using a Nyquist plot of the electrochemical impedance analysis.

\section{Introduction}

Commercially available supercapacitors still abide by low energy densities which are incapable of being exchanged for a battery as a power source. ${ }^{1,2}$ Pseudo capacitors and electrical double layer capacitors (EDLCs) are the two categories of supercapacitor electrode materials owing to their fast reduction, oxidation and reversible reaction pseudocapacitance that can produce a higher capacitance and energy density than EDLCs. ${ }^{3-5}$ Owing to the presence of the functional groups containing oxygen, graphene demonstrates a higher capacitance. To increase the energy density and potential window of the working device, electrode materials play a vital role in a supercapacitor. ${ }^{6}$ As the alloys and noble metals are very costly and have poisoning effects, ${ }^{7}$ low-cost nanostructures of transition metal oxides, such as $\mathrm{NiO},{ }^{3} \mathrm{CuO},{ }^{8} \mathrm{Fe}_{2} \mathrm{O}_{3}, \mathrm{Gd}^{9}$ and $\mathrm{Co}_{3} \mathrm{O}_{4}{ }^{10}$ are often used for high storage supercapacitors. Owing to the large surface area, chemical stability and high conductivity graphene

Department of Chemistry, Anna University, Chennai, 600 025, Tamil Nadu, India . E-mail: pandurangan_a@yahoo.com; Fax: +91 44 22200660; Tel: +91 4422358653 $\dagger$ Electronic supplementary information (ESI) available. See DOI: 10.1039/c8ra08762h is used as a substrate for the metals and metal oxides. ${ }^{\mathbf{1 1 , 1 2}}$ In transition metal oxides, hydroxides and layered materials restrict their applications in supercapacitors, as they produce pseudocapacitance in a lower potential window $(V) \cdot{ }^{13-15}$ Hence it is crucial to improve the capacitance and energy density to favour the demands of energy storage.

Owing to the dual EDLC and pseudo capacitive nature, high conductivity associating metal nanoparticles and carbon electrodes were employed. ${ }^{16,17}$ Multilayer graphene is used as an electrode to give excellent conductivity in supercapacitors. ${ }^{\mathbf{1 8 - 2 0}} \mathrm{It}$ has been shown that charging and discharging occurred on the surface of the electrode materials, rather than in the bulk ${ }^{\mathbf{2 1}}$. Owing to the establishment of defect sites, the conduction of the electrons decreases owing to uninterrupted charging and discharging. The decrease in resistance raises the conductivity of the electron between the electrode materials and the current collectors and minimizes the $I R$ drop..$^{22}$

Introduction of a heteroatom into the graphene alters the $\mathrm{d}$ band and enhances the electron donation to the parent metals. ${ }^{23}$ Doping of boron onto a $\mathrm{sp}^{2}$ bonded hexagonal carbon framework induces a p-type semiconductor, as the boron atom has three valence electrons, one electron less than the carbon atom, which enhances the performance of electrochemical 
reactions. $^{\mathbf{4 , 2 4}}$ The electronic transport properties of graphene were improved by incorporation of boron onto the carbon lattice of graphene. ${ }^{25}$ The amount of boron atoms doped into the graphene nanosheets plays a major role in tailoring the band gap energy. Boron doped onto carbon and graphite can improve the coulombic efficiency and energy storage capacitance of anodic materials ${ }^{\mathbf{2 6}, 27}$. Long-term cyclic stability for electrochemical retention can be obtained owing to the oxygen containing functional groups in the boron doped graphene nanosheets. ${ }^{28-31}$ Hence, boron doped porous graphene was used to enhance the electrochemical performance of a prepared material that had both pseudo and electric double layer capacitance (EDLC).

The operating voltage of the supercapacitor can be improved to $0-2.0 \mathrm{~V}$ by the development of an asymmetric supercapacitor. ${ }^{32}$ An asymmetric solid-state supercapacitor (ASSC) is the combination of the positive material of a battery type pseudo capacitor and the capacitive type negative materials of a porous carbon in the same electrolyte to utilise their different negative and positive electrode potential windows. ${ }^{33-35}$ Among the transition metal oxides $\mathrm{CuO}$ is one of the least expensive, has an environmentally friendly nature and has greater stability which can be used to tailor the supercapacitor, giving the electrode materials more intense energy and power densities. $^{36,37} \mathrm{CuO}$ used in supercapacitor applications has various nanostructures such as nanorods, nanowires, nanosheets, nanoribbons and flowers. ${ }^{38-40}$

The resistance of copper to oxidation is very poor, hence carbon shells on graphene nanosheets were used to encapsulated the $\mathrm{Cu}$ nanoparticles. However, bare nanoparticles of $\mathrm{Cu}$ oxidized to $\mathrm{Cu}_{2} \mathrm{O}$ within a few hours at room temperature. The copper nanocore was shielded by the $\mathrm{C}$ shells, and protected them from further oxidation. Usually, the conductivity of carbon shells is very poor, hence by using boron the conductivity of carbon is significantly increased and the material has greater stability. Accordingly, single layer $\mathrm{C}$ atoms on the $\mathrm{Cu}$ passivates the oxidation by an adsorption-diffusion mechanism. ${ }^{41}$ Furthermore, above $1000{ }^{\circ} \mathrm{C}$ the $\mathrm{Cu}$ nanoparticles melt, hence anchoring of copper on the carbon lattice of graphene is difficult. ${ }^{42,43}$ The transformation of $\mathrm{Cu}(\mathrm{II})$ to the $\mathrm{Cu}(\mathrm{I})$ species in the charge/discharge process provides evidence of a redox reaction in the high-performance supercapacitor.

The asymmetric supercapacitor of $\mathrm{CuO}$ with activated carbon shows the highest capacitance of $83 \mathrm{Fg}^{-1}$ with the potential window of $1.6 \mathrm{~V}$ in $\mathrm{KOH}^{44} \mathrm{CuO} / \mathrm{CNT}$ and $\mathrm{CuO} / \mathrm{rGO}$ with a specific capacitance of $137.6 \mathrm{Fg}^{-1}$ and $163.7 \mathrm{Fg}^{-1}$ in a $\mathrm{KOH}$ electrolyte was reported by Liu et al. ${ }^{\mathbf{4 5 4}}$ and Zhao et al. described $\mathrm{CuO}$ on graphene with a specific capacitance of 331.9 $\mathrm{Fg}^{-1}$ in $6 \mathrm{M} \mathrm{KOH}$ as the electrolyte. ${ }^{47}$

To the best of our knowledge, the investigation of copper nanoparticles anchored boron doped graphene nanosheets (CuBG) has not previously been reported, based on our literature review. In the present study, CuBG samples were successfully synthesized using a two-step hydrothermal method followed by pyrolysis of the material in a chemical vapor deposition (CVD) reactor at different temperatures in an $\mathrm{Ar}$ atmosphere. Incorporation of boron (heteroatom) on the copper functionalized graphene can be used to produce energy storage devices with a long cyclic stability. Here, we report for the first time the synthesis and characterization of CuBG samples with an excellent electrochemical performance both in $\mathrm{H}_{2} \mathrm{SO}_{4} / \mathrm{PVA}$ and $\mathrm{KOH} / \mathrm{PVA}$ solid electrolytes. ASSC devices were fabricated and attained a maximum energy density (132.5 $\mathrm{W} \mathrm{h} \mathrm{kg}^{-1}$ ) and power density (1000 $\mathrm{W} \mathrm{kg}^{-1}$ ) using a $\mathrm{H}_{2} \mathrm{SO}_{4} / \mathrm{PVA}$ solid electrolyte. Using a $\mathrm{KOH} / \mathrm{PVA}$ solid electrolyte, the realized energy density and power density was $31.1 \mathrm{~W} \mathrm{~h} \mathrm{~kg}^{-1}$ and $800 \mathrm{~W} \mathrm{~kg}^{-1}$ respectively.

Herein, we designed and fabricated a symmetric and an asymmetric supercapacitor with copper anchored boron-doped graphene nanosheet as the electrode materials on the graphene sheet with $\mathrm{H}_{2} \mathrm{SO}_{4} / \mathrm{PVA}$ as the solid electrolyte. This paper highlights the performance of the supercapacitor, which has a specific capacitance of $483 \mathrm{Fg}^{-1}$ at $1 \mathrm{Ag}^{-1}$ in the symmetric supercapacitor and $238 \mathrm{Fg}^{-1}$ at $1 \mathrm{Ag}^{-1}$ in the ASSC with an extended potential window of $2.0 \mathrm{~V}$, these results show that the copper anchored boron doped graphene nanosheet is a promising electrode material for use in an electrochemical supercapacitor. Furthermore, in a single asymmetric device we used a $2 \mathrm{~V}$ green color LED to determine the long-life stability, which emits a constant glow of light in the range 0 to $134 \mathrm{~s}$ with regular decreases in power. After $140 \mathrm{~s}$ an even power was maintained for a small interval of time (in seconds). This shows the high energy and power density can transfer electrons much faster between the electrode materials and within the solid electrolytes of the flexible ASSC device.

\section{Materials and methods}

\section{Materials}

Graphite powder $(\sim 25 \mu \mathrm{m})$, concentrated sulphuric acid $\left(\mathrm{H}_{2} \mathrm{SO}_{4}\right)$, potassium permanganate $\left(\mathrm{KMnO}_{4}\right)$, sodium nitrate $\left(\mathrm{NaNO}_{3}\right)$, concentrated hydrochloric acid $(\mathrm{HCl})$, boron trioxide $\left(\mathrm{B}_{2} \mathrm{O}_{3}\right)$ and copper sulphate pentahydrate $\left(\mathrm{CuSO}_{4} \cdot 5 \mathrm{H}_{2} \mathrm{O}\right)$, were purchased from Sigma Aldrich-India for the synthesis of GO and $\mathrm{CuBG}$, all were used without further purification. 2D water was used for the entire preparation and purification process.

\section{Synthesis of graphene oxide}

Graphene oxide was prepared by using synthetic graphite powder as a starting material $(<20 \mu \mathrm{m}$, with a purity of $99.99 \mathrm{wt} \%$, Aldrich). The GO synthesis process is described as follows: $1 \mathrm{~g}$ graphite powder, $0.5 \mathrm{~g}$ sodium nitrate $\left(\mathrm{NaNO}_{3}\right)$ and $23 \mathrm{ml}$ of concentrated sulfuric acid $\left(\mathrm{H}_{2} \mathrm{SO}_{4}\right)$ were added into a $500 \mathrm{ml}$ round bottom flask kept at $5{ }^{\circ} \mathrm{C}$ in an ice bath with constant stirring for $15 \mathrm{~min}$. Then, $3 \mathrm{~g}$ of potassium permanganate $\left(\mathrm{KMnO}_{4}\right)$ was added slowly into the flask. The reaction temperature was maintained for $2 \mathrm{~h}$ at $5{ }^{\circ} \mathrm{C}$ and then the reaction temperature was slowly raised to $35^{\circ} \mathrm{C}$ and maintained for another $30 \mathrm{~min}$ with vigorous stirring. Deionized (DI) water (46 $\mathrm{ml}$ ) was added to the suspension and the temperature was increased to $98{ }^{\circ} \mathrm{C}$. The mixture was kept at the same temperature with continuous stirring for $30 \mathrm{~min}$. To complete the reaction $140 \mathrm{ml}$ of DI water and $10 \mathrm{ml}$ of hydrogen peroxide 
$(10 \% \mathrm{v} / \mathrm{v})$ were added. A yellowish-brown product was obtained. The resulting product of GO was washed with $5 \%$ diluted $\mathrm{HCl}$ solution. To remove the acid and $\mathrm{Mn}$ ions, the solution was warmed at $70{ }^{\circ} \mathrm{C}$ respectively. The product was later centrifuged and dried at $60{ }^{\circ} \mathrm{C}$ for 24 hours.

\section{Synthesis of copper anchored boron doped graphene nanosheet}

Copper sulphate $(10 \mathrm{mg}$ ) was dissolved in $100 \mathrm{ml}$ of ethanol with mechanical stirring for two days and $10 \mathrm{mg}$ of $\mathrm{B}_{2} \mathrm{O}_{3}$ was added to the solution and allowed to stir for $2 \mathrm{~h}$ to completely dissolve the particles, $10 \mathrm{mg}$ GO was added to the solution and it was sonicated for $30 \mathrm{~min}$ to achieve the complete dispersion of all particles. The mixtures were transferred into an autoclave and heated at $150{ }^{\circ} \mathrm{C}$ for $12 \mathrm{~h}$. To remove the unreacted and amorphous substances, the product was washed with DI water several times and dried at $60{ }^{\circ} \mathrm{C}$ for $12 \mathrm{~h}$. CuBG1 was prepared by heating the obtained product at $150-550{ }^{\circ} \mathrm{C}$ in a CVD reactor under an Ar atmosphere. The product obtained was washed using DI water and dried at $60{ }^{\circ} \mathrm{C}$ for $12 \mathrm{~h}$. Similarly, CuBG2, CuBG3, CuBG4 and CuBG5 were prepared at the different temperatures of $650{ }^{\circ} \mathrm{C}, 750{ }^{\circ} \mathrm{C}, 850{ }^{\circ} \mathrm{C}$ and $950{ }^{\circ} \mathrm{C}$ respectively. Above $1000{ }^{\circ} \mathrm{C}$ the material becomes crystalline.

\section{Characterization techniques}

Material characterization. The as synthesized materials were analysed using X-ray diffraction (XRD) on a PANalytical High Resolution XRD (PW 3064/60) in a $2 \theta$ range from 5 to $90^{\circ}$ with $\mathrm{Cu} \mathrm{K} \alpha$ radiation $(\lambda=1.5406 \AA)$ operated at $30 \mathrm{~mA}, 40 \mathrm{kV}$ to give structural conformation. Raman spectra were conducted using a confocal Raman microscope (Model WITech GmbH, CRM Alpha 300S) at room temperature and a charge coupled device (CCD) detector with a helium neon laser wavelength of $633 \mathrm{~nm}$. The microstructure and the morphology of graphene oxide and $\mathrm{Cu}$-B-doped GO were canvased using a field emission scanning electron microscope (FESEM) FEI Quanta FEG 200 at an accelerating voltage of $3.0 \mathrm{kV}$ and high resolution transmission electron microscopy (HRTEM, S-Twin F20 TECHNAI G ${ }^{2}$ ). The elemental composition on the surface and the chemical nature of the samples were studied using X-ray photo electron spectroscopy (XPS) using a Kratos analytical spectrometer with a monochromatic $\mathrm{Al} \mathrm{K} \alpha$ radiation of $10 \mathrm{~mA}$ and $15 \mathrm{kV}$. According to the $\mathrm{C} 1 \mathrm{~s}$ peak at $284.6 \mathrm{eV}$ all of the spectra were corrected. The background subtraction and curve fitting were carried out using Casa XPS software.

Electrochemical measurements. The solid-state symmetric and asymmetric supercapacitor electrochemical properties, such as cyclic voltammetry (CV), galvanostatic charge-discharge (GCD) and electrochemical impedance spectroscopy (EIS)Nyquist plot of the as-synthesized copper nanoparticles anchored on the boron doped graphene nanosheet were investigated using an Autolab-PGSTAT302N electrochemical work station with $\mathrm{H}_{2} \mathrm{SO}_{4}$ /PVA as a solid electrolyte. The electrode active materials were prepared by making a paste of CuBG and polyvinylidene fluoride (PVDF) in a mass ratio of $9: 1$ in the absence of any other conducting material, $1 \mathrm{ml}$ of $N$-methyl-2- pyrrolidone (NMP) was added and the material was ground well in a mortar and pestle for $10 \mathrm{~min}$ to attain a homogeneous slurry. The prepared activated slurry was painted onto the graphite sheet evenly and allowed to dry at $80{ }^{\circ} \mathrm{C}$ overnight. Using a similar method the symmetric supercapacitor was prepared by sandwiching CuBG4 and CuBG5 with $\mathrm{H}_{2} \mathrm{SO}_{4} / \mathrm{PVA}$ as the solid electrolyte, additional care must be taken while preparing the symmetric device. From these, the capacitance was calculated in the two electrode system, and the mass ratio of the electrode was obtained using the charge-balance theory.

Cyclic voltammetry was performed in the potential window of -0.4 to $0.2 \mathrm{~V}$ at a different scan rate. The gravimetric capacitance of the two electrode system was calculated using the formula:

$$
C_{\mathrm{s}}=\frac{1}{r m\left(V_{1}-V_{0}\right)} \int_{V_{0}}^{V_{1}} I(v) \mathrm{d} V
$$

In which, $r$ is the scan rate $\left(\mathrm{mV} \mathrm{s}^{-1}\right), m$ is the mass of active material $(\mathrm{g})$ in the electrode, $V_{0}, V_{1}$ are the initial and final voltage windows (V) and $I$ is the current (A).

A charge-discharge experiment was conducted in different potential windows at different current densities of $1,2,3,4,5$, 10 and $20 \mathrm{Ag}^{-1}$. The specific gravimetric capacitance $\left(C_{\mathrm{s}}\right)$ was calculated using eqn $(2)^{48}$

$$
C_{\mathrm{s}}=2 \frac{Q \Delta T}{V-i R}
$$

In which, $Q$ is the current density during the discharge process (A), $\Delta T$ is the discharge time (s), $V$ is the potential window difference and $i R$ is the internal resistance voltage drop at the beginning of the discharge.

The energy density $\left(E, \mathrm{~W} \mathrm{~h} \mathrm{~kg}{ }^{-1}\right)$ and power density $(P, \mathrm{~W}$ $\mathrm{kg}^{-1}$ ) were calculated using the specific capacitance obtained from the charge-discharge.

$$
\begin{gathered}
E=\frac{C_{\mathrm{s}} \times \Delta V^{2}}{2 \times 3.6} \\
P=\frac{E}{t} \times 3600
\end{gathered}
$$

In which, $t$ is the discharge time.

Synthesis of $\mathrm{H}_{2} \mathrm{SO}_{4} / \mathrm{PVA}$ and $\mathrm{KOH} / \mathrm{PVA}$ electrolyte. The solid electrolyte of $\mathrm{H}_{2} \mathrm{SO}_{4} / \mathrm{PVA}$ used for the device was prepared by adding $3 \mathrm{ml}$ of $\mathrm{H}_{2} \mathrm{SO}_{4}$ into $30 \mathrm{ml}$ of distilled water under constant stirring, $3 \mathrm{~g}$ of polyvinyl alcohol powder (PVA) was then added to the solution. The mixture was stirred at $85{ }^{\circ} \mathrm{C}$ until a clear solution was obtained and then allowed to cool to room temperature in a Petri dish. Similarly, $4 \mathrm{~g}$ of $\mathrm{KOH}$ and $6 \mathrm{~g}$ of PVA powder was added to $20 \mathrm{ml}$ of distilled water at $85{ }^{\circ} \mathrm{C}$ to give formation of a gel.

Fabrication of symmetric and asymmetric supercapacitors. The flexible solid-state asymmetric supercapacitor was assembled with graphene nanoplatelets as the positive electrode and copper nanoparticles anchored on a boron doped graphene nanosheet as the negative electrode. The working electrode was prepared by using $\mathrm{H}_{2} \mathrm{SO}_{4} / \mathrm{PVA}$ as the solid-state electrolyte and separator. From the preliminary investigation of the prepared 
samples, CuBG5, CuBG4 and CuBG3 were used to fabricated the ASSC. Initially the surface of the graphite sheet was activated by treating the sheet under ultrasonication for $15 \mathrm{~min}$ in ethanol and it was dried at $60{ }^{\circ} \mathrm{C}$ for $15 \mathrm{~min}$. The slurry was prepared by mixing CuBG and PVDF in the mass ratio of $9: 1$, and was ground well to achieve a uniform mixing before $1 \mathrm{ml}$ of NMP was added and it was mixed for a further $10 \mathrm{~min}$. The paste of the slurry was coated onto the sheet evenly and dried at $80{ }^{\circ} \mathrm{C}$ for $1 \mathrm{~h}$. Similarly, the graphene nanoplatelets were also coated on another sheet. Both the ionic electrodes were sandwiched with a $\mathrm{H}_{2} \mathrm{SO}_{4} / \mathrm{PVA}$ electrolyte under $1 \mathrm{~atm}$ pressure. The thickness between the two electrodes was $1 \mathrm{~mm}$, allowing the device to obtain an interface between electrodes for a day. For the design of the symmetric supercapacitor device, copper nanoparticles anchored onto a boron doped graphene nanosheet were employed as both the positive and negative electrode and the fabrication procedure was same as that described above.

\section{Results and discussions}

\section{Positive electrode material}

The XRD pattern for GO gives a peak at $2 \theta=11^{\circ}$ corresponding to a (001) reflection (Fig. 1a). The $d$-space of GO was calculated to be $0.79 \mathrm{~nm}$, which is much higher than graphite, this is due to the harsh oxidation of the graphite. The insertion of an oxygenated functional group on the graphite is attributed to the interlayer space of the GO. ${ }^{49}$ The structure of the crystal and the crystalline size of the prepared nanoparticles were investigated using the wide angle XRD pattern shown in Fig. 1a. From the spectra, the clear and strong peak for CuBG4, CuBG5 at $2 \theta=$ $43.5^{\circ}, 50.6^{\circ}, 74.27^{\circ}$ corresponds to (111), (200) and (220) (JCPDS04-0836), which indicates the formation of highly pure cubic crystalline $\mathrm{Cu}^{50}$ nanoparticles on the graphene nanoplatelets. The XRD pattern for CuBG1, CuBG2 and CuBG3 not only shows the high crystalline peak (111), but also (200) and (220) of the cubic crystalline $\mathrm{Cu}$ and also the minor diffraction peaks at $2 \theta=$ $35.5^{\circ}, 38.8^{\circ}$ and $61.4^{\circ}$ correspond to the formation of a monoclinic phase of CuO (JCPDS: 05-0661). ${ }^{37,51,52}$

The XRD pattern confirms the formation of highly crystalline $\mathrm{CuO}$ for the samples prepared at $550{ }^{\circ} \mathrm{C}, 650^{\circ} \mathrm{C}$ and $750{ }^{\circ} \mathrm{C}$ from their corresponding peak positions. The samples prepared at $850{ }^{\circ} \mathrm{C}$ and $950{ }^{\circ} \mathrm{C}$ reveal metallic $\mathrm{Cu}$ in their structure. There is no other impurity peaks and secondary phases were obtained for the prepared CuBG samples. From the XRD pattern, it is noted that the sample that was prepared above $850{ }^{\circ} \mathrm{C}$ shows only metallic copper and the peak at $24^{\circ}$ also confirms the

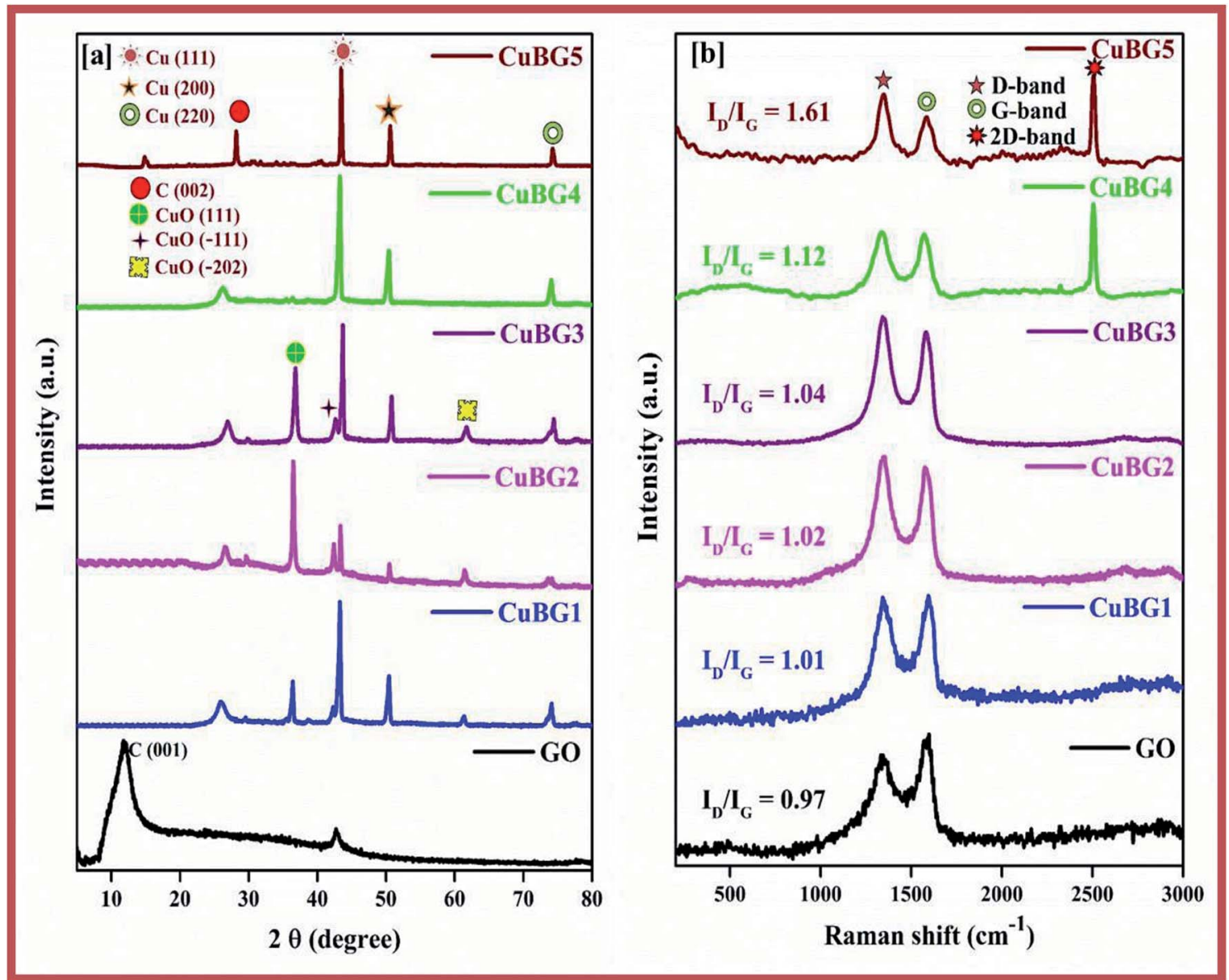

Fig. 1 (a) Wide angle XRD spectra of GO, CuBG1, CuBG2, CuBG3, CuBG4 and CuBG5. (b) Raman spectra of GO, CuBG1, CuBG2, CuBG3, CuBG4 and CuBG5. 

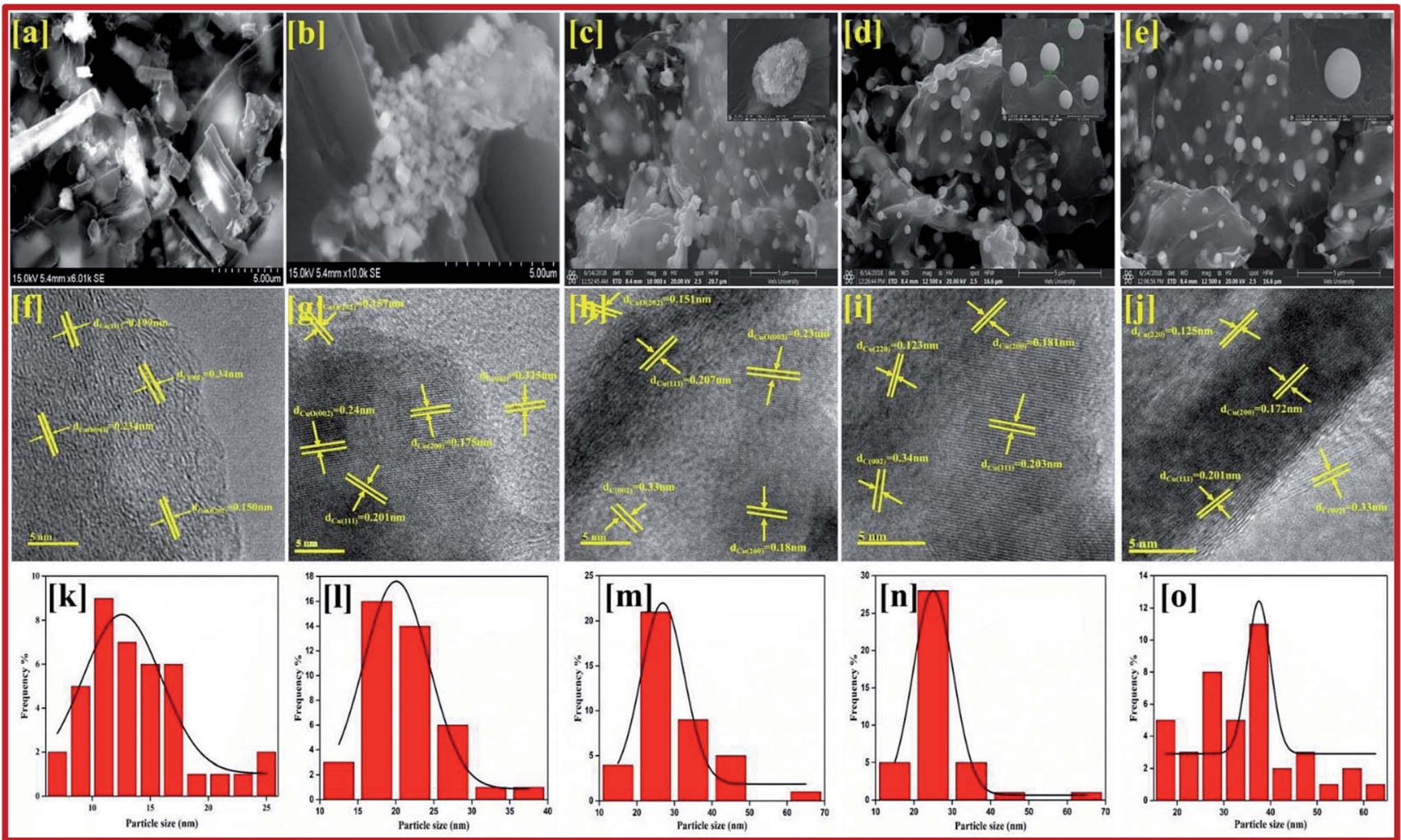

Fig. 2 FESEM images of (a) CuBG1; (b) CuBG2; (c) CuBG3; (d) CuBG4; and (e) CuBG5. HRTEM images of (f) CuBG1; (g) CuBG2; (h) CuBG3; (i) CuBG4; and (j) CuBG5 at high magnification. $(\mathrm{k}-\mathrm{O})$ Particle size distribution histogram of prepared CuBG samples.

presence of boron doped graphene. At a high temperature $(>850$ ${ }^{\circ} \mathrm{C}$ ) all of the copper based oxide materials become reduced even in an air atmosphere, owing to the carbon shell encapsulation of the $\mathrm{Cu}$ nano metal particles. Here, the copper nanocore was shielded by the $\mathrm{C}$ shells and this protected them from further oxidation. Accordingly, the single layer $\mathrm{C}$ atoms on the $\mathrm{Cu}$ passivates the oxidation at high temperatures by an adsorptiondiffusion mechanism. ${ }^{41} \mathrm{~A}$ further increase in temperature, that is, above $1000{ }^{\circ} \mathrm{C}$, and the $\mathrm{Cu}$ nanoparticles melt, hence the anchoring of copper on the carbon lattice of graphene is difficult. $^{42,43}$ Using the software XRDA 3.1 the lattice parameters were estimated for the corresponding peaks which were found to be $a=b=c=3.5925 \pm 0.0075 \AA$ with cell volume $V=46.367$ $\AA^{3}$ for CuBG5, $3.6219 \pm 0.0020 \AA$ with cell volume $V=47.512 \AA^{3}$ for CuBG4, $3.5943 \pm 0.0075 \AA$ with cell volume $V=46.436 \AA^{3}$ for CuBG3, $3.6205 \pm 0.0140 \AA$ with cell volume $V=47.459 \AA^{3}$ for CuBG2 and 3.6191 $\pm 0.0015 \AA$ with cell volume $V=47.403 \AA^{3}$ for CuBG4. Using the Debye-Scherrer equation the crystallite sizes of the prepared samples were calculated using the formula:

$$
D=k \lambda / \beta \cos \theta
$$

In which, $D$ the average crystallite size, $\beta$ the full width at half maximum of the individual peak, $k$ is the shape factor and $\theta$ the diffraction angle. The approximate crystallite size calculated using the Debye-Scherrer equation is $24 \mathrm{~nm}$, which was further confirmed using HRTEM particle size analysis.
HRTEM particle size analysis was used to distinguish the disordered and ordered structure of the $\mathrm{C}-\mathrm{C}$ bonds, carbonmetal bonds and carbon heteroatom. It is evident from Fig. 1b, that two peaks were obtained at $1334.58 \mathrm{~cm}^{-1}$ and $1559.4 \mathrm{~cm}^{-1}$, indicating the incorporation of the metal and boron on the graphene sheet. The defects in the carbon materials were reflected in the $\mathrm{D} / \mathrm{G}$ ratio. The $I_{\mathrm{D}} / I_{\mathrm{G}}$ ratio of the CuBG1, CuBG2, CuBG3, CuBG4 and CuBG5 are 1.0, 1.01, 1.033, 1.21 and $1.6 \mathrm{~cm}^{-1}$ respectively, which was evidently larger than graphene oxide at $1.0 \mathrm{~cm}^{-1}$ respectively, this ratio demonstrated that metal and boron atom insertion causes structural defects on the graphene sheet. The small peak at $2504.35 \mathrm{~cm}^{-1}$ indicates the multilayer of the graphene sheet, in comparison, CuBG4 and CuBG5 show a large 2D band which reflects the formation of the multi-layer compounds. This was further confirmed from the FESEM and HRTEM analysis.

The qualified morphologies of CuBG1 obtained using FESEM are shown in Fig. 2a. This shows the presence of a large number of copper nanoparticles on the graphene nanoplatelets. The small nanorods of the copper and boron particles have clearly migrated all over the sheets. In Fig. 2b, CuBG2 appears with a large number of carbon nanoparticles in the shape of rods in the graphene sheet and boron balls become attached inside the nanoplatelets of graphene. Fig. 2c-e shows the uniform morphology of the dandelion and global shaped copper nanoparticles on the graphene nanoplatelets. The dandelion shaped single particles are shown in the inset image. 
From CuBG3, CuBG4 and CuBG5, as the temperature increases the insertion of copper and boron nanoparticles increases with regular separation of the particles without the occurrence of aggregation on the graphene nanoplatelets.

From Fig. $2 \mathrm{f}-\mathrm{j}$ it can be seen that the copper particles migrated onto the graphene sheet regularly, whereas the large particles were framed on the sheet owing to the separation of the individual particles during calcination at high temperatures. The fringes of the metal particles on the sheet can be clearly observed in the high-resolution images. From the measured particle size, it can be seen that most of the particles are in the range of $20-30 \mathrm{~nm}$ and also a large number of smaller particles are dispersed on the sheet. In the higher magnification, patches of the metals and fringes of boron on the graphene sheet were identified. From the TEM images at a low magnification range of $50 \mathrm{~nm}$, the particles size was calculated using Image software and cumulative distribution of the particle size on the graphene sheet is given in the graph shown in Fig. $2 \mathrm{k}-\mathrm{o}$. It can be seen from Fig. 2n, that CuBG4 has a regular distribution of particles at a particle size of $24 \mathrm{~nm}$. Using the high magnification images the interlayer distance between the fringes was also calculated to be $5 \mathrm{~nm}$ using Image J software and this correlated with the XRD $d$-spacing. In addition, using the selected areas electron diffraction (SAED) pattern the $h k l$ planes were identified from their corresponding $d$-spacing calculation using the relationship:

$$
d_{h k l}=L \lambda / r
$$

in which, $d$ represents the inter-planar $d$-spacing, $L$ represents the distance between the camera and the sample, $\lambda$ is the wavelength of the incident electron beam used in the analysis and $r$ is radius of the diffraction rings in the SAED pattern.

The SAED pattern in the Fig. 3 shows the high crystalline nature with different rings and clearly indicates the transformation of the particles. CuBG4 and CuBG5 show only three circles corresponding to the carbon (002), copper (111) and copper (200) plane. Whereas, the other samples of CuBG1, CuBG2 and CuBG3 show different circles, which correspond to the carbon (002), $\mathrm{Cu}$ (111), $\mathrm{Cu}(200), \mathrm{CuO}(111)$ and $\mathrm{CuO}(-111)$. Thus, the transformation of materials at different temperatures was further confirmed using the HRTEM images.

The chemical composition and valence state of the elements were evaluated using the patterns obtained using X-ray photoelectron spectroscopy (XPS), which were similar for the copper and boron graphene nanoplatelet catalysts with two different temperature of $750{ }^{\circ} \mathrm{C}$ and $850{ }^{\circ} \mathrm{C}$. The high resolution deconvoluted $\mathrm{Cu} 2 \mathrm{p}$ spectrum is predicted in Fig. $4 \mathrm{c}$ and $\mathrm{f}$. The high intense peak at a binding energy of around $953.0 \mathrm{eV}$ represents $\mathrm{Cu} 2 \mathrm{p}_{1 / 2}$ and the peak for $\mathrm{Cu} 2 \mathrm{p}_{3 / 2}$ appearing at a lower energy, 932.5 eV, respectively, can be attributed to the $\mathrm{Cu}^{+} / \mathrm{Cu}^{0}{ }^{8,53}$ state, which confirms that the copper exists on the sheet of graphene as the metallic phase. In contrast, the peaks at $933.4 \mathrm{eV}$ and 953.8 eV corresponds to the $\mathrm{Cu}^{2+}$ characteristic peaks at $\mathrm{Cu} 2 \mathrm{p}_{3 / 2}$ and $\mathrm{Cu} 2 \mathrm{p}_{1 / 2}$ respectively, which shows that $\mathrm{CuO}$ is present on the graphene sheet. ${ }^{54}$ Further peaks at the higher binding energies of $941.6 \mathrm{eV}$ and $961.8 \mathrm{eV}$ imply the presence of $\mathrm{Cu}^{2+}$ ions,${ }^{55}$ which indicates the presence of $\mathrm{CuO}$, whereas the $\mathrm{Cu}^{2+}$ of cupric oxide in the $3 \mathrm{~d}^{9}$ configuration appears as the hole in the $3 \mathrm{~d}$ band. The $\mathrm{Cu}^{+}$of cuprous oxide has a completely filled $\mathrm{d}-$ orbital $\left(3 \mathrm{~d}^{10}\right)$, only the $4 \mathrm{~s}$ band is unoccupied. ${ }^{56}$ The fine gap between the $\mathrm{Cu} 2 \mathrm{p}_{1 / 2}$ and $\mathrm{Cu} 2 \mathrm{p}_{3 / 2}$ is about $21 \mathrm{eV}$, which provides evidence for the $\mathrm{CuO}$ spectrum. ${ }^{57}$ This determination also corresponds to the X-ray diffraction patterns.

Fig. $4 \mathrm{a}$ and $\mathrm{d}$ show the $\mathrm{C} 1 \mathrm{~s}$ peak, and Fig. $4 \mathrm{~b}$ and e show the B1s peak of CuBG3 and CuBG4. Using the Gaussian Lorentz peak, curve fitting was carried out after correction of the Shirleybackground. The peak at a binding energy of $284.3 \mathrm{eV}$ was assigned to $\mathrm{C}=\mathrm{C}$. The chemical shift of $0.8-1.3 \mathrm{eV}$ was assigned to the hydroxyl group of $\mathrm{C}-\mathrm{OH}$, the peak shift at 4-5 eV corresponds to the acid $(-\mathrm{COOH})$ group, the carbonyl group $(\mathrm{C}=\mathrm{O})$ was assigned to the shift of 2.65-3.45 eV and the shift of peak from $0.0-5.5 \mathrm{eV}$ was assigned to the carbonate group $(\mathrm{O}=\mathrm{C}=\mathrm{O})$ group, respectively. ${ }^{25,58,59}$ The peak ratio of $\mathrm{C}=\mathrm{C}$ in the graphene sheets decreases with an increase in the conjugation of the oxygen functional group with the boron and copper nanoparticles. Owing to the harsh oxidation on graphite, the functional group of the oxygen becomes incorporated on $\mathrm{C}-\mathrm{C}$, which has already been proved using XRD.

The peak at $187.2 \mathrm{eV}$ is assigned to $\mathrm{B}-\mathrm{C}$ and the peak at $188.9 \mathrm{eV}$ corresponds to $\mathrm{B}_{4} \mathrm{C}$ and the boron substituted carbon. ${ }^{60,61}$ The presence of the B 1 s peak at $186 \mathrm{eV}$ confirms the intercalation of boron on the graphene sheet. The B 1s peak of CuBG3 has the highest peak at $186.4-189.36 \mathrm{eV}$ and this is deconvoluted into four small peaks at 185.6, 186.4, 189.4 and $192 \mathrm{eV}$ which corresponds to the clusters of boron $(185.3 \mathrm{eV})$, $\mathrm{B}_{4} \mathrm{C}(186.4 \mathrm{eV})$ and $\mathrm{BC}_{3}(189.4 \mathrm{eV})$ respectively. ${ }^{62,63}$ The single peak at a higher binding energy of $192.6 \mathrm{eV}$ corresponds to the oxides of boron $\mathrm{BC}_{2} \mathrm{O}$ and $\mathrm{BCO}_{2}$ respectively. ${ }^{64}$ The $\mathrm{B} 1$ s peak of CuBG4 shows the highest peak at $190.32 \mathrm{eV}$ and four small peaks at a high binding energy of 189.7, 188.1, 190.6 and $191.4 \mathrm{eV}$ respectively, which confirms the replacement of the carbon atom in the honey comb lattice by boron $(188.1 \mathrm{eV}), \mathrm{BC}_{3}$ $(189.7 \mathrm{eV})$ and the oxides of boron $\mathrm{BCO}_{2} / \mathrm{BC}_{2} \mathrm{O}(190.6 \mathrm{eV})$, respectively. Thus, the XPS confirms the incorporation of the boron atom on the carbon lattice of the graphene sheets, the peaks at a higher binding energy prove that the boron is bonded with the carbon and oxygen atoms. ${ }^{65}$ The deconvoluted XPS peak of oxygen is shown in Fig. S1. $\dagger$

\section{Electrochemical performance of the CuBG electrodes in $\mathrm{H}_{2} \mathrm{SO}_{4} /$ PVA}

Negative electrode materials. The electrochemical cyclic performance and capacitance of the electrode material CuBG were evaluated using $\mathrm{CV}$ and GCD techniques in a two-electrode system with $\mathrm{H}_{2} \mathrm{SO}_{4} / \mathrm{PVA}$ as the solid electrolyte at different electric current densities $\left(1 \mathrm{Ag}^{-1}\right.$ to $\left.20 \mathrm{Ag}^{-1}\right)$ with a potential difference of -0.4 to $0.2 \mathrm{~V}$.

It can be seen from Fig. 4a that the redox peaks on the $\mathrm{CV}$ impose the performance of double-layered capacitance. The CV curve of the prepared samples are shown in Fig. S2. $\dagger$ The shifting of the anodic peak from 0.012 to $0.08 \mathrm{~V}$ corresponds to the copper oxidation from $\mathrm{Cu}(\mathrm{I})$ to $\mathrm{Cu}(\mathrm{II})$ as the scan rate 


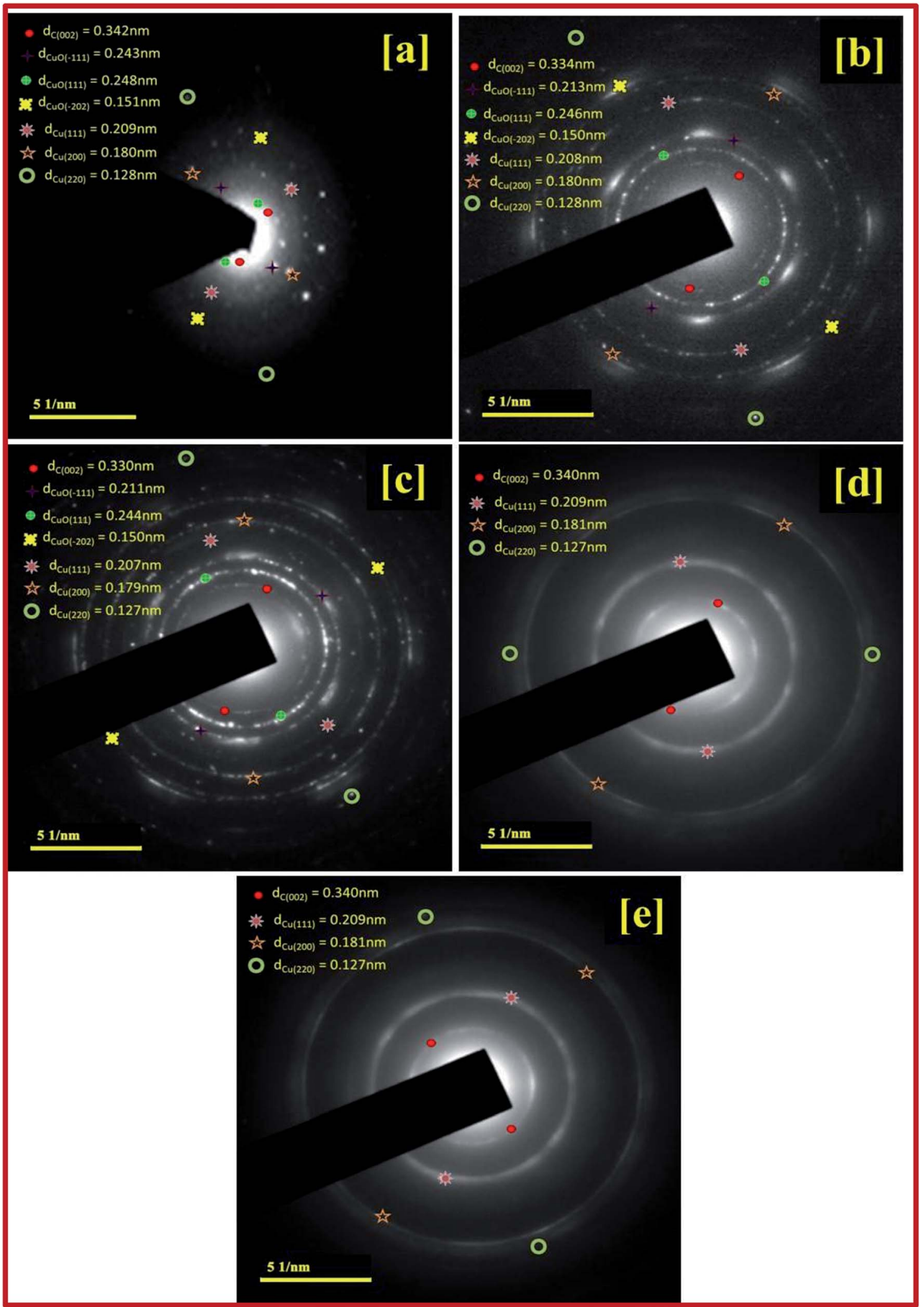

Fig. 3 SAED pattern for: (a) CuBG1; (b) CuBG2; (c) CuBG3; (d) CuBG4; and (e) CuBG5.

decreases from 100 to $10 \mathrm{mV} \mathrm{s}^{-1}$ and cathodic peaks shifts from -0.06 to $-0.012 \mathrm{~V}$ and imparts the reduction of $\mathrm{Cu}(\mathrm{II})$ to $\mathrm{Cu}(\mathrm{I})$ respectively. The $\mathrm{CV}$ curve of the sample shows the ideal rectangular curve of EDLC, whereas boron on the graphene sheet produces a pseudocapacitance behaviour. From Fig. S2, $\dagger$ as the scan rate increases there is no significant change in the 

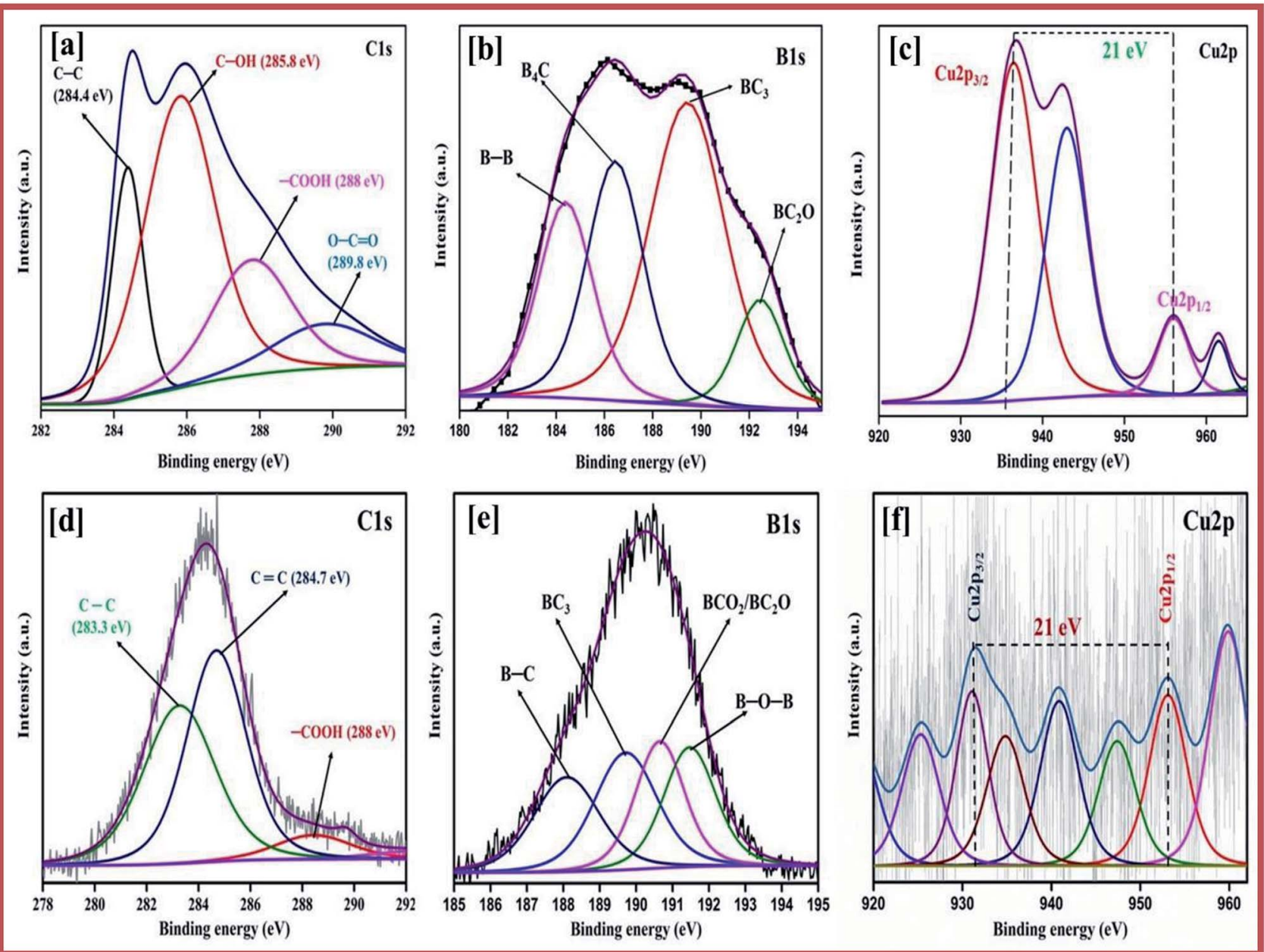

Fig. 4 Deconvoluted XPS spectra of C 1s of (a) CuBG3 and (d) CuBG4; B 1s of (b) CuBG3 and (e) CuBG4; and Cu 2p of (c) CuBG3 and (f) CuBG4.

shape of the CV curve, which indicates the excellent conductivity of the electrode materials..$^{\mathbf{4 0}}$ As the scan rate increases, the cathodic peak shifted towards a more negative direction, this is the internal resistance of the electroactive material. The different charge storage mechanisms that take place on the surface of the electrode are based on the adsorption/desorption of $\mathrm{H}^{+}$ions on the surface.

$$
\begin{gathered}
\mathrm{Cu} \rightarrow \mathrm{Cu}^{2+}+2 \mathrm{e}^{-} \\
\mathrm{Cu}^{2+}+\mathrm{e}^{-} \rightarrow \mathrm{Cu}^{+} \\
2 \mathrm{CuO}+2 \mathrm{H}^{+}+2 \mathrm{e}^{-} \rightarrow \mathrm{Cu}_{2} \mathrm{O}+\mathrm{H}_{2} \mathrm{O}
\end{gathered}
$$

For the materials prepared at a high temperature of $850{ }^{\circ} \mathrm{C}$ and $950{ }^{\circ} \mathrm{C}$, metallic copper also plays a major role in the $\mathrm{CV}$ and charge-discharge curve. At a low temperature of 550, 650 and $750{ }^{\circ} \mathrm{C}$, the boron and oxygen containing groups in boron and copper play a vital role, and hence the materials prepared at low temperature show a EDLC layer. At high temperature, the copper oxide and copper hydroxide gets transformed to metallic $\mathrm{Cu}$ and hence both EDLC and pseudo capacitance exists in CV.
The anodic and cathodic peak of CuBG4 was larger than that of CuBG5, which indicates the oxidation of $\mathrm{Cu}$ to $\mathrm{Cu}(\mathrm{II})$ and the reduction of $\mathrm{Cu}(\mathrm{II})$ to $\mathrm{Cu}(\mathrm{I})$. The peak at the potential of $0.1 \mathrm{~V}$ indicates oxidation of metallic $\mathrm{Cu}$ to $\mathrm{Cu}^{2+}$.

The resistivity of copper is $1.68 \times 10^{-8} \Omega \mathrm{m}$, whereas the conductivity of copper is $5.96 \times 10^{7} \sigma\left(\mathrm{S} \mathrm{m}^{-1}\right)$ which has a much higher conductivity than the semiconductor CuO. The highly pure copper gives $100 \%$ conductivity, and metallic copper is more stable than unstable $\mathrm{CuO}$ and very unstable $\mathrm{Cu}_{2} \mathrm{O}$.

Evidently, in Fig. 5a the anodic and cathodic peak of CuBG4 was larger than the other, which indicates the oxidation $\mathrm{Cu}$ to $\mathrm{Cu}$ (II) and the reduction of $\mathrm{Cu}$ (II) to $\mathrm{Cu}(\mathrm{I})$. The conductivity of metallic copper is higher compared to the semiconductors of $\mathrm{CuO}, \mathrm{Cu}_{2} \mathrm{O}$ and $\mathrm{Cu}(\mathrm{OH})_{2}$.

By calculating the integral area from the curve, the specific capacitance was calculated and plotted against the different scan rates in Fig. 5b. From the figure it can be seen that as the scan rate increases there is a constant decrease in the specific capacitance. Comparing the area of the electrode materials, CuBG4 shows a larger area than the others. At the scan rate of 100 to $10 \mathrm{mV} \mathrm{s}^{-1}$ the specific capacitance of CuBG5 increases from 186 to $281 \mathrm{Fg}^{-1}$, the capacitance of CuBG4 increases from 219 to 


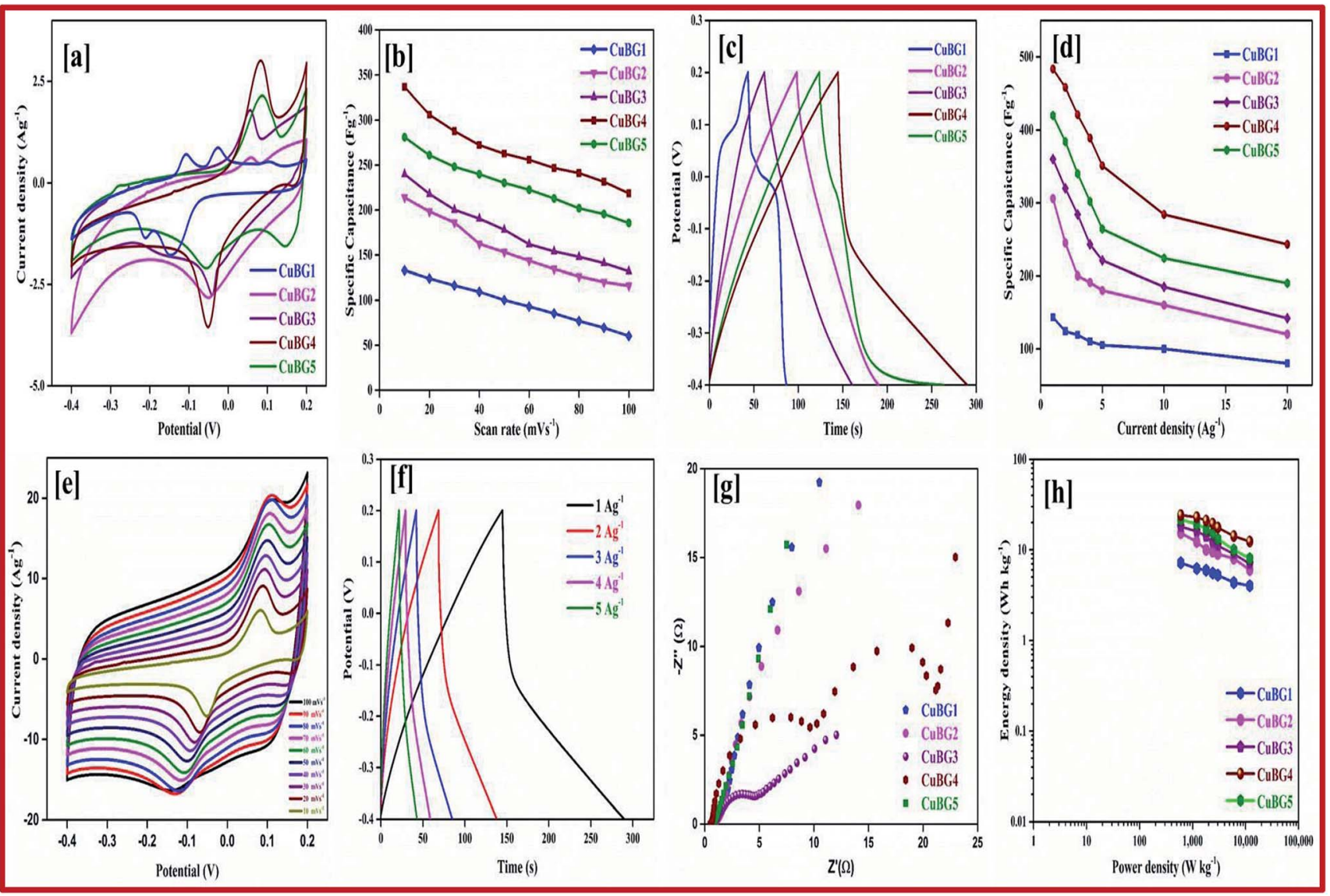

Fig. 5 (a) CV of all CuBG samples at a scan rate of $2 \mathrm{mV} \mathrm{s}^{-1}$. (b) Variation of specific capacitance of the CuBG samples at different scan rates. (c) Charge/discharge curve of CuBG samples at $1 \mathrm{Ag}^{-1}$. (d) Specific capacitance of samples at different current densities from $1 \mathrm{Ag}^{-1}$ to $20 \mathrm{Ag}^{-1}$. (e) CV of CuBG4 at different scan rates of $100-10 \mathrm{mV} \mathrm{s}^{-1}$. (f) Charge/discharge curve of CuBG4 at different current densities from 1 to $20 \mathrm{Ag}{ }^{-1}$. (g) EIS-Nyquist plot of all CuBG samples. (h) Energy and power density of all samples calculated from the discharge time at different current densities.

$336.6 \mathrm{Fg}^{-1}$, CuBG3 from 132 to $240 \mathrm{Fg}^{-1}$, CuBG2 from 116 to 214 $\mathrm{Fg}^{-1}$ and CuBG1 from 60 to $133 \mathrm{Fg}^{-1}$, respectively. This shows that as the scan rate decreases the specific capacitance increases, which is assigned to the diffusion effect of the electrolyte ions. ${ }^{66}$

Fig. 5c presents the galvanostatic charge/discharge curve of the CuBG at different temperatures at the current density of 1 $\mathrm{Ag}^{-1}$, the charge/discharge curves of all of the samples are shown in Fig $\mathrm{S} 2 \dagger$ at current densities from 1 to $10 \mathrm{Ag}^{-1}$ respectively. From the charging curve, the high capacitance yield in the -0.4 to $0.2 \mathrm{~V}$ potential window corresponds to the oxidation of $\mathrm{Cu}(\mathrm{I})$ to $\mathrm{Cu}$ (II) as evidenced by the $\mathrm{CV}$ curve. In the discharge curve there are two regions with a fast $I R$ drop potential and a slow decay potential.

The pseudocapacitive nature of $\mathrm{Cu}$ in the CuBG electrodes is evidenced in the charge/discharge of the non-linear curve. The longer charge/discharge of the CuBG4 indicates a higher specific capacitance of $483 \mathrm{Fg}^{-1}$ compared to CuBG5 $\left(420 \mathrm{Fg}^{-1}\right)$, CuBG3 $\left(360 \mathrm{Fg}^{-1}\right)$, CuBG2 $\left(306 \mathrm{Fg}^{-1}\right)$ and CuBG1 $\left(143 \mathrm{Fg}^{-1}\right)$ at 1 $\mathrm{Ag}^{-1}$ respectively. The specific capacitances were calculated for the samples at different current densities and are plotted in Fig. 5 d. From the graph it can be seen that as the current density increases there is a gradual decrease in the specific capacitance owing to the increase in the $I R$ drop and at high current densities, demonstrating that the active materials were insufficient in the redox reaction ${ }^{67}$. The cyclic stability of the electrode materials was evaluated using GCD at $5 \mathrm{Ag}^{-1}$ for 5000 cycles. Fig. S3† shows the capacitance retention and coulombic efficiency of CuBG1 (a), CuBG2 (b), CuBG3 (c), CuBG4 (d) and CuBG5 (e) at different cycle numbers. The capacitance of CuBG4 decreases from 351 to $331 \mathrm{Fg}^{-1}$ after 5000 cycles. The specific capacitance decreases gradually, this is due to the interaction of the copper nanoparticles and boron on the matrix of the graphene sheet. The application of electrode materials for supercapacitor devices is calculated using the energy density and power density.

The kinetics of the interfacial charge transport mechanism between the electrodes was analyzed in the two-electrode system in the frequency range of $1 \mathrm{MHz}$ to $0.1 \mathrm{~Hz}$ for an applied open circuit potential (OCP) at room temperature. Fig. $5 \mathrm{~g}$ represents the EIS-Nyquist plots of the prepared samples (CuBG1, CuBG2, CuBG3, CuBG4 and CuBG5) which shows two semicircle trends for the corresponding two interfacial charge transport processes. The first semicircle in the high frequency region is attributed to total charge transport resistance $\left(R_{\mathrm{ct} 1}\right)$ at 
Table 1 Electrochemical parameters for the EIS-Nyquist plot

\begin{tabular}{llrrrrl}
\hline Sample & $R_{\mathrm{s}}(\Omega)$ & $R_{\mathrm{ct} 1}(\Omega)$ & $R_{\mathrm{ct} 2}(\Omega)$ & $C_{\mu}(\mathrm{F})$ & \multicolumn{1}{l}{$W_{\mathrm{s}}$} & $\chi^{2}$ \\
\hline CuBG1 & 0.94 & 13.79 & 42.83 & 0.037 & 0.152 & $5.96 \times 10^{-3}$ \\
CuBG2 & 0.93 & 1.99 & 13.86 & 0.174 & 0.121 & $5.43 \times 10^{-3}$ \\
CuBG3 & 0.91 & 5.54 & 9.53 & 0.324 & 1.137 & $5.80 \times 10^{-3}$ \\
CuBG4 & 0.69 & 0.43 & 32.61 & 0.101 & 0.126 & $2.30 \times 10^{-3}$ \\
CuBG5 & 0.85 & 11.73 & 12.63 & 0.073 & 0.157 & $1.63 \times 10^{-3}$
\end{tabular}

the electrolyte/electrode material interface and the mid frequency semicircle contributes to the total charge transport resistance $\left(R_{\mathrm{ct} 2}\right)$ at the interface of the CuBG grain interior. The intersection of the semicircle on the real part of the impedance provides the distinct interfacial charge transport resistance of the samples. $R_{\mathrm{S}}$ represents the combined effect of the surface resistance of the electrode (carbon felt) and the diffusion resistance of the electrolyte ions, $C_{\mu}$ is the total chemical capacitance and $W_{\mathrm{s}}$ is the Warburg diffusion resistance. Here, the obtained semicircles were fitted using equivalent circuit modelling and the parameters of the electrochemical fit are summarized in Table 1.

It is noted from Table 1, that $R_{\mathrm{S}}$ appears to be equal owing to the utilization of the same carbon felt as the electrode material for all of the prepared devices. Furthermore, the charge transport resistance $\left(R_{\mathrm{ct} 2}\right)$ at the electrolyte/electrode material interface is very low in CuBG4 compared to the other samples which reveals efficient charge transportation in the CuBG4 material/ electrolyte interface. This is responsible for the high specific capacitance obtained by the EDLC behavior in the CuBG4 based asymmetric supercapacitor device. However, $R_{\mathrm{ct} 2}$ seems to be very high for all of the samples (CuBG) owing to the charge transport resistance at the grain interior. Although the $R_{\mathrm{ct} 2}$ for the CuBG4 sample is high, its specific capacitance is greater than the other samples owing to the presence of low $R_{\mathrm{ct} 1}$. In addition to the pseudo-capacitive nature of the CuBG4 material, the low $R_{\mathrm{ct} 1}$ offers a high EDLC behaviour which is responsible for the high specific capacitance in CuBG4. The change in the charge transport resistance before and after the cycle stability test was evaluated using the EIS-Nyquist plot.

The Ragone plot shows the energy and power density of the materials, this is an important parameter for determining the performance of the supercapacitor devices. Fig. $5 \mathrm{~h}$ shows the power density versus energy density at various current densities for all of the symmetric devices. From the plot it is evident that CuBG4 shows the highest energy density of $24.13 \mathrm{~W} \mathrm{~h} \mathrm{~kg}^{-1}$ at a power density of $600 \mathrm{~W} \mathrm{~kg}^{-1}$ at $1 \mathrm{Ag}^{-1}$, which is higher than the other devices of CuBG5 $21.6 \mathrm{~W} \mathrm{~h} \mathrm{~kg}^{-1}$, CuBG3 $18 \mathrm{~W} \mathrm{~h} \mathrm{~kg}^{-1}$, CuBG2 $15.31 \mathrm{~W} \mathrm{~h} \mathrm{~kg}^{-1}$ and CuBG1 $7.1 \mathrm{~W} \mathrm{~h} \mathrm{~kg}^{-1}$ at the same power density of $600 \mathrm{~kW} \mathrm{~kg}^{-1}$ calculated from the discharge area of the current density $1 \mathrm{Ag}^{-1}$. Thus, this result establishes that CuBG4 has a high energy and power density in a wide potential window, which is suitable for use in the supercapacitor devices.

Positive electrode material. In the ASSC, rGO have been used as the anode material, as they have a high surface area and are low cost. The performance of the rGO electrode material was tested in three electrode supercapacitors with platinum wire as the counter electrode and $\mathrm{Ag} / \mathrm{AgCl}$ as the reference electrode. Fig. 6a shows the cyclic voltammetry of rGO at different scan rates from 100 to $10 \mathrm{mV} \mathrm{s}^{-1}$ in the potential range of $0-1.0 \mathrm{~V}$. The quasi-rectangular shape of the $\mathrm{CV}$ curve indicates the charge stored in the electrode dominated the high double layer capacitance. The capacitance was calculated by integrating the $\mathrm{CV}$ curve. The retainment of the rectangular shape even at a lower scan rate without any distortion shows a splendid rate performance implicit in the fast-discharge property of graphene. Reduced graphene nanoplatelets show a capacitance of $169 \mathrm{Fg}^{-1}$ in an electrolyte owing to the correlation of the high energy density with a small pore size and high-power density with a large pore size. Moreover, rGO shows a specific capacitance of 169, 145, 128 and $103 \mathrm{Fg}^{-1}$ at different scan rates of 10 , 20, 30 and $50 \mathrm{mV} \mathrm{s}^{-1}$ (Fig. 6b) respectively. Fig. 6c shows the cyclic stability of rGO at the $1^{\text {st }}, 1000^{\text {th }}$ and $2000^{\text {th }}$ cycles, this confirms a capacitance retention of $94 \%$ after 2000 cycles.

Fig. $6 \mathrm{~d}$ shows the GCD of rGO at different current densities of $1,2,3,4,5$ to $10 \mathrm{Ag}^{-1}$. The equilateral triangular charge/ discharge of $\mathrm{rGO}$ shows the high stability of the materials. Fig. 6e shows a regular decrease in the specific capacitance with an increase in the current density. The cyclic stability has also been calculated at $1 \mathrm{Ag}^{-1}$ for 5000 cycles. The first and last five cycles are plotted inside the capacitance retention graph plotted in Fig. 6f, this produces a 95\% retention with a decrease of specific capacitance from $142 \mathrm{Fg}^{-1}$ to $135 \mathrm{Fg}^{-1}$.

Asymmetric solid-state supercapacitor in $\mathrm{H}_{2} \mathrm{SO}_{4} / \mathrm{PVA}$. Regarding the redox character, the composites of CuBG nanoparticles have a high capacitance compared to rGO owing to the fast-ion transport. Using these two materials, positive and negative electrodes were fabricated for an asymmetric supercapacitor, respectively. In both the two and three electrode materials the electrochemical properties were evaluated with a static window potential for the electrode materials of $\mathrm{rGO}$ for the synthesized materials. In the asymmetric supercapacitor, the copper-boron-doped graphene oxide acts as a cathode and the graphene oxide as an anode, which is denoted as $\mathrm{rGO} / /$ CuBG. By combining the two electrodes of rGO and CuBG, the cyclic voltammetry of each electrode was estimated in a twoelectrode system with stable potential windows of $0-1 \mathrm{~V}$ for rGO and -0.4 to $0.2 \mathrm{~V}$ for CuBG, which meant that the constructed device of $\mathrm{rGO} / / \mathrm{CuBG}$ accomplished a potential window of $2 \mathrm{~V}$. According to the equation, $1 / C_{\text {total }}=1 / C_{\text {cathode }}+1 / C_{\text {anode }}$, the positive and negative electrode charge storage capacitances were balanced to produce a maximum capacitance for the fabricated device. As the positive electrode (rGO), negative electrode (CuBG) potential window and specific capacitance were different, the loading of the mass on these two electrodes was adjusted to balance the charge storage capacity. Using the charge balance theory $\left(Q_{+}=Q_{-}\right)$, the negative to positive mass ratio was calculated using the following equation: ${ }^{68,69}$

$$
\begin{gathered}
m_{+} \times C_{\mathrm{s}^{+}} \times \Delta V_{+}=m_{-} \times C_{\mathrm{s}-} \times \Delta V_{-} \\
m_{+} / m_{-}=\left(C_{-} \times \Delta V_{-}\right) /\left(C_{+} \times \Delta V_{+}\right)
\end{gathered}
$$



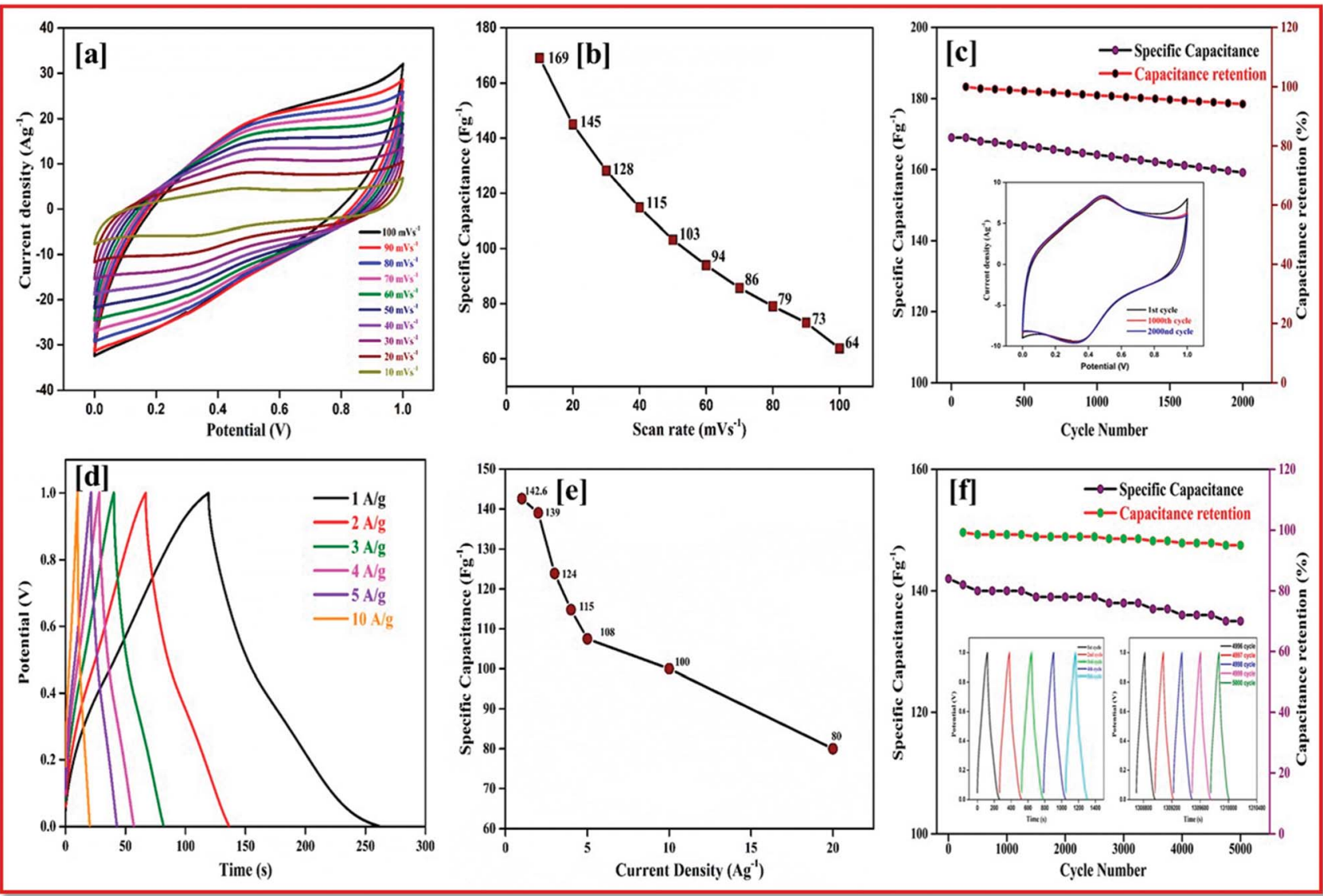

Fig. 6 (a) CV of rGO at different scan rates. (b) Specific capacitance at different scan rates from 100 to $10 \mathrm{mV} \mathrm{s}^{-1}$. (c) Specific capacitance and capacitance retention calculated using the CV curve, cyclic stability for 2000 cycles. (d) Charge/discharge curve of rGO at different current densities. (e) Specific capacitance at different current densities. (f) Specific capacitance and capacitance retention for a long cyclic stability of 5000 cycles at $5 \mathrm{Ag}^{-1}$.

in which, $Q_{+}, Q_{-}, m_{+}, m_{-}, C_{+}, C_{-}, \Delta V_{+}, \Delta V_{-}$are the charges, mass, capacitance and potential windows of the (positive) anode and (negative) cathode obtained in the symmetric two electrode and three electrodes.

Fig. 7b shows the CV curve of the fabricated asymmetric solidstate device at different potential voltages at a scan rate of $50 \mathrm{mV}$ $\mathrm{s}^{-1}$ collected for the two electrode systems. This proves that the device can operate up to a wide voltage of $2 \mathrm{~V}$. Both the rGO and nanoparticles of the copper anchored boron doped graphene nanoplatelets are pseudo capacitors with a high specific capacitance. The properties of our asymmetric supercapacitor can be ascribed to the individual properties of the positive and negative electrode and their combination.

The rectangular curve of the $\mathrm{CV}$ shows the retention of the capacitance at different scan rates without the loss of the $\mathrm{CV}$ curve, irrespective of the potential windows from $0-2 \mathrm{~V}$ at $50 \mathrm{mV}$ $\mathrm{s}^{-1}$ is shown in Fig. 7d. At the highest cell voltage of $2.0 \mathrm{~V}$, the ASSC exhibits a redox-peak and a substantial rectangular shaped $\mathrm{CV}$, which designates the co-operation of EDLC and the pseudocapacitance. Compared with the symmetric device, the redox peak at ASSC was lower. At a low scan rate of $10 \mathrm{mV} \mathrm{s}^{-1}, 180 \mathrm{Fg}^{-1}$ of specific capacitance was obtained, even at a high scan rate of $100 \mathrm{mV} \mathrm{s}^{-1} 128 \mathrm{Fg}^{-1}$ of specific capacitance was still retained.
Galvanostatic charge-discharge measurement play a vital role in the asymmetrical soli-state supercapacitor to calculate the specific capacitance at different current densities and rate capabilities up to 5000 cycles. In various current densities the GCD of the device was evaluated (Fig. S10†). In Fig. 7e, the charge-discharge of the device at different potentials is shown at $0.5 \mathrm{Ag}^{-1}$, this shows a regular charge and discharge at various potentials of $0.8-2.0 \mathrm{~V}$. The specific capacitance of the device at different potentials was calculated at a current density of 0.5 $\mathrm{Ag}^{-1}$ and plotted in Fig. 7f. In a high potential window of $2.0 \mathrm{~V}$, from the slope of the discharge curve the specific capacitance was $238.5 \mathrm{Fg}^{-1}$ at a current density of $1.0 \mathrm{Ag}^{-1}$. The specific capacitance of $125 \mathrm{Fg}^{-1}$ was obtained at a high current density of $20 \mathrm{Ag}^{-1}$. Even at a high current density the specific capacitance was almost $52.5 \%$, this highlights that even at a high current density the device remains at maximum capacitance. The insertion of the first and last cycle in the cyclic stability also establish the same result. Interestingly, the charge-discharge of the supercapacitor and our asymmetric supercapacitor device were similar only at a low current density of $0.5 \mathrm{Ag}^{-1}$. In Fig. 8c at a current density of $5 \mathrm{Ag}^{-1}$, the cyclic stability of the asymmetric supercapacitor was measured up to 5000 cycles, and even after 5000 cycles $91 \%$ of the capacitance was retained without 

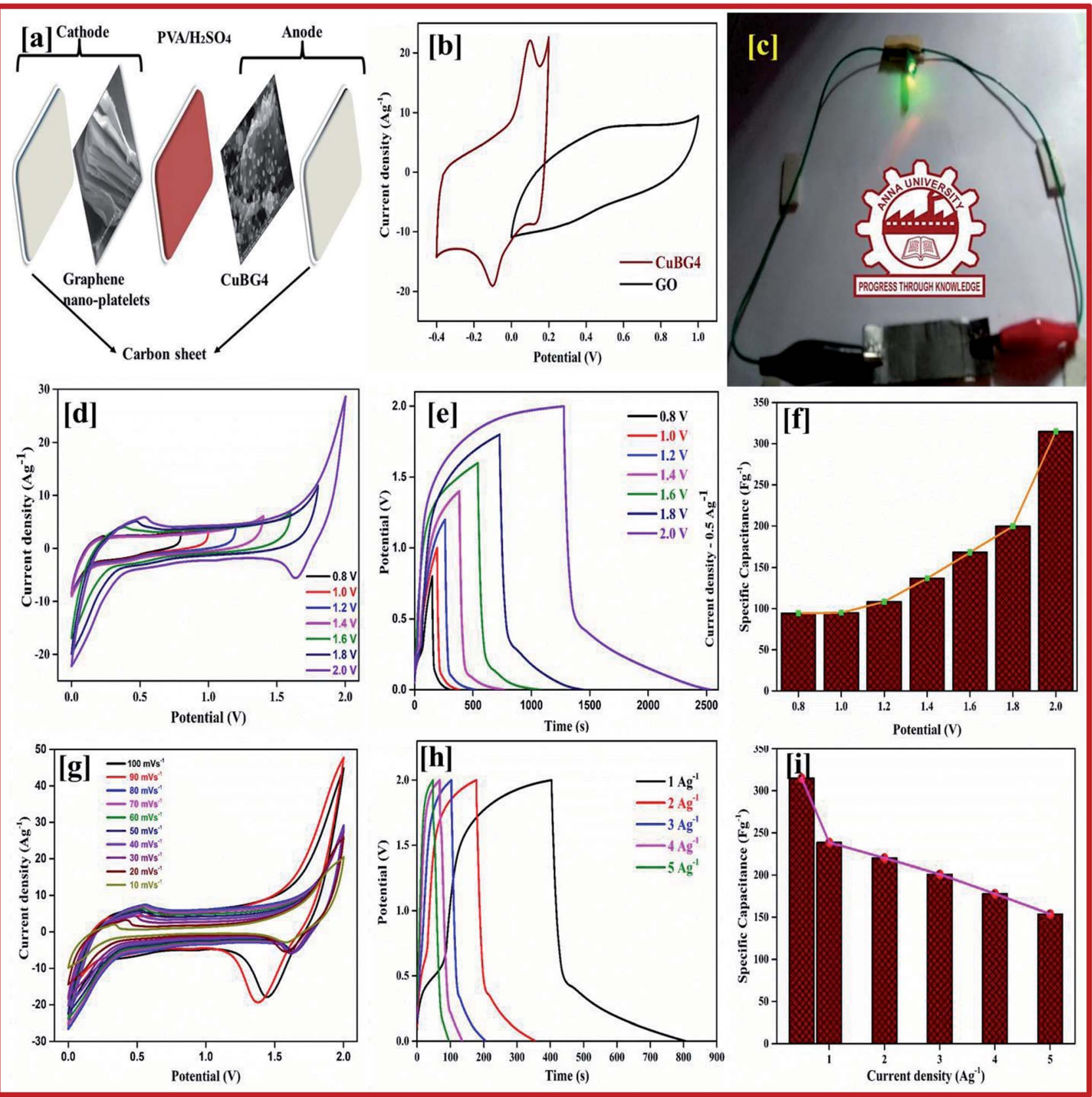

Fig. 7 (a) Schematic diagram of CuBG4. (b) CV of rGO//CuBG4 device at $50 \mathrm{mV} \mathrm{s}^{-1}$. (c) 2 V LED being illuminated with an ASSC device. (d) CV curve of CuBG4 at different potentials from 0.8 to $2.0 \mathrm{~V}$. (e) Charge-discharge curve of CuBG4 at different potentials from 0.8 to $2.0 \mathrm{~V}$. (f) Specific capacitance of CuBG4 at different potential windows. ( $g$ and $h$ ) CV and charge-discharge curve of CuBG4 at different scan rates in a high potential of $2.0 \mathrm{~V}$; and (i) the specific capacitance of CuBG4 at different current densities from 1 to $20 \mathrm{Ag}^{-1}$ in the highest potential of $2.0 \mathrm{~V}$.

destruction of the charge-discharge. During the stability process the coulombic efficiency was close to $100 \%$. Fig. $8 \mathrm{a}$ shows the specific capacitance of the device at different potentials of $0.8,1.0,1.2,1.4,1.6,1.8$ and $2 \mathrm{~V}$ and at different current densities (from 1 to $20 \mathrm{Ag}^{-1}$ ), from the graph it can be seen that the capacitance is stable up to a high current density.

Electrical impedance studies were carried out for all of asymmetric supercapacitor devices in the frequency range of $100 \mathrm{kHz}$ to $0.01 \mathrm{~Hz}$. The fast ion transport between the positive and negative electrode was confirmed using a Nyquist plot as shown in Fig. 8d. The $R_{\mathrm{S}}$ equivalent series resistance represents the intercept of the first point on the real axis $Z^{\prime}(\Omega)$. In contrast, both the spectra show a straight line in the low frequency region, which indicates the excellent supercapacitor behaviour of the electrode. In the high frequency region an arc shape indicates the high stability in the electrochemical reaction. From the spectra, even after 5000 cycles, the value of $R_{\mathrm{S}}$ is almost unchanged and a slight increase in the $R_{\mathrm{ct}}$ value is obtained. 

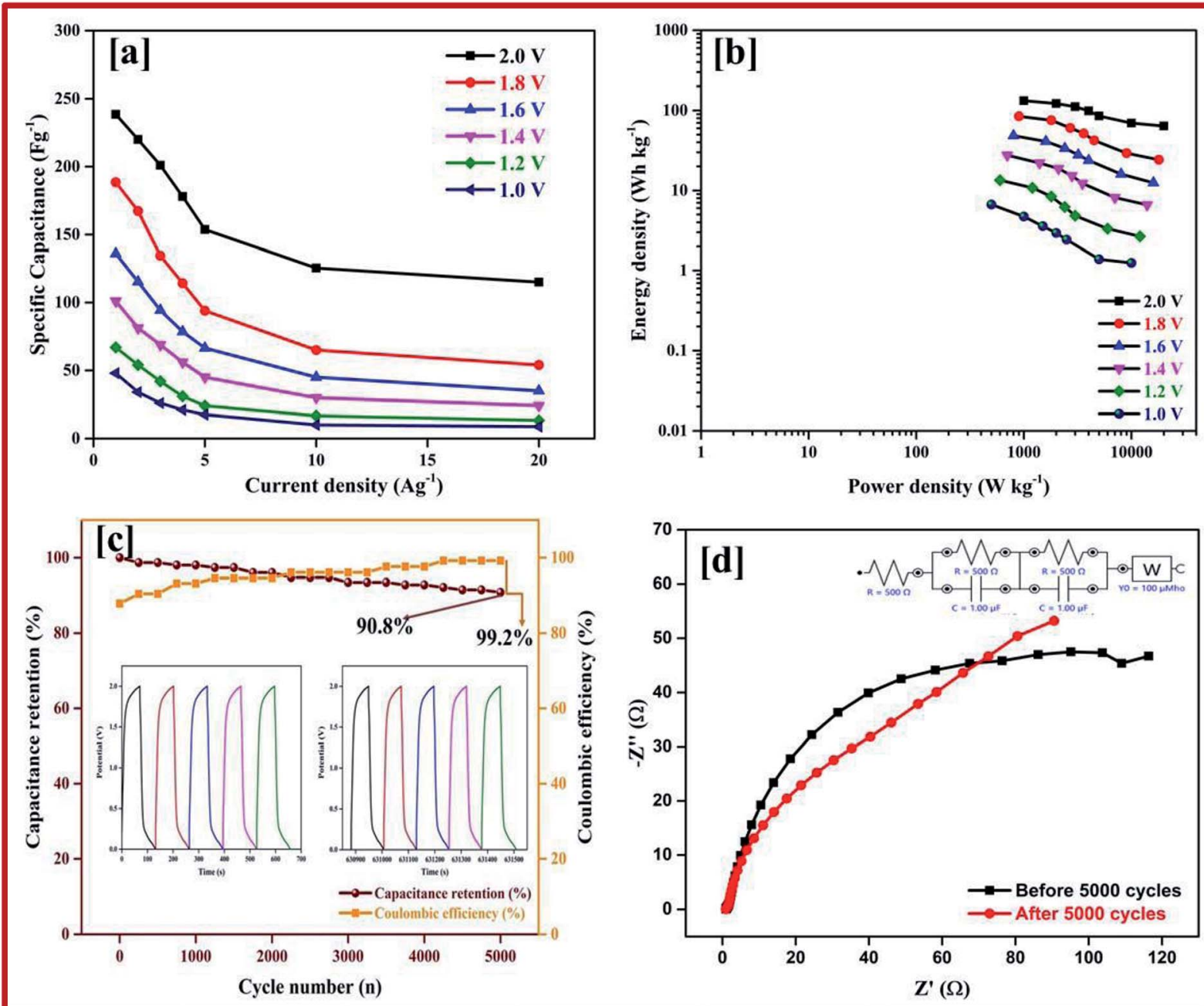

\begin{tabular}{|l|c|c|c|c|c|c||}
\hline Sample & $\mathrm{R}_{\mathrm{s}}(\Omega)$ & $\mathrm{R}_{\mathrm{ct} 1}(\Omega)$ & $\mathrm{R}_{\mathrm{ct} 2}(\Omega)$ & $\mathrm{C}_{\mu}(\mathrm{F})$ & $\mathrm{W}_{\mathrm{s}}$ & $\chi^{2}$ \\
\hline Before & 0.9027 & 0.1 & 37.8 & 0.2542 & 0.2339 & $1.608 \mathrm{E}-03$ \\
\hline After & 0.9321 & 4.16 & 37.82 & 0.2837 & 0.2472 & $1.133 \mathrm{E}-02$ \\
\hline
\end{tabular}

Fig. 8 (a) Specific capacitance at different potentials and at different current densities from 1 to $20 \mathrm{Ag}^{-1}$ calculated from the discharge curve. (b) Energy and power density calculated from the specific capacitance at different potentials and at different current densities. (c) Percentage of capacitance retention and percentage of coulombic efficiency of rGO//CuBG4 for 5000 cycles. (d) Nyquist plot before and after the cyclic stability test of 5000 cycles, the inset shows the circuit used for the calculation and the table showing the electrochemical studies is shown.

The high performance of the fabricated device was evaluated using a Ragone plot, which determines the relationship between the energy density $(E)$ and power density $(P)$. The energy density of $\mathrm{rGO} / / \mathrm{CuBG} 4\left(132.5 \mathrm{~W} \mathrm{~h} \mathrm{~kg}^{-1}\right)$ was much higher than the other asymmetric devices of $\mathrm{rGO} / /$ CuBG5 (112.2 $\mathrm{W} \mathrm{h} \mathrm{kg}^{-1}$ ) and rGO//CuBG3 (101.3 $\left.\mathrm{W} \mathrm{h} \mathrm{kg}^{-1}\right)$ at a same power density of $1000 \mathrm{~W} \mathrm{~kg}^{-1}$ in a cell voltage of $2.0 \mathrm{~V}$. Significantly, without forfeiting the power density the ASSC renders a high energy density. The energy density of $\mathrm{rGO} / / \mathrm{CuBG} 4$ was $132.5 \mathrm{~W} \mathrm{~h} \mathrm{~kg}^{-1}$ at a current density of 1.0 $\mathrm{Ag}^{-1}$, even when the power density increased to $20000 \mathrm{~W}$ $\mathrm{kg}^{-1}$, the energy density was maintained at up to $63.88 \mathrm{~W} \mathrm{~h} \mathrm{~kg}^{-1}$ at a current density of $20 \mathrm{Ag}^{-1}$. The maximum energy density obtained for $\mathrm{rGO} / / \mathrm{CuBG} 4$ was $132.5 \mathrm{~W} \mathrm{~h} \mathrm{~kg}^{-1}$ at a current density of $1 \mathrm{Ag}^{-1}$, which is much higher than that reported for other asymmetric supercapacitors (Table S1 $\dagger$ ). Fig. 8b shows the energy and power density of the $\mathrm{rGO} / /$ CuBG4 for different potentials at different current densities, this shows that the energy and power density remains constant with the increase from a low potential to a high potential without any disturbance in the charge-discharge. Similarly, the other two devices of rGO//CuBG3 (Fig. S4-S6†) and $\mathrm{rGO} / / \mathrm{CuBG} 5$ (Fig. S7-S9†) are also given in the ESI $\uparrow$ for further comparison. The electrochemical function of the fabricated solid-state asymmetric supercapacitor can be assigned by the combination of highly crystalline nanoparticles of copper anchored on a boron doped graphene nanosheet with $\mathrm{rGO}$ electrodes, the cells are fabricated using the gel electrolyte containing a polymer and $\mathrm{H}_{2} \mathrm{SO}_{4}$ to give a fast ion transfer and to reduce the cost of the device. 


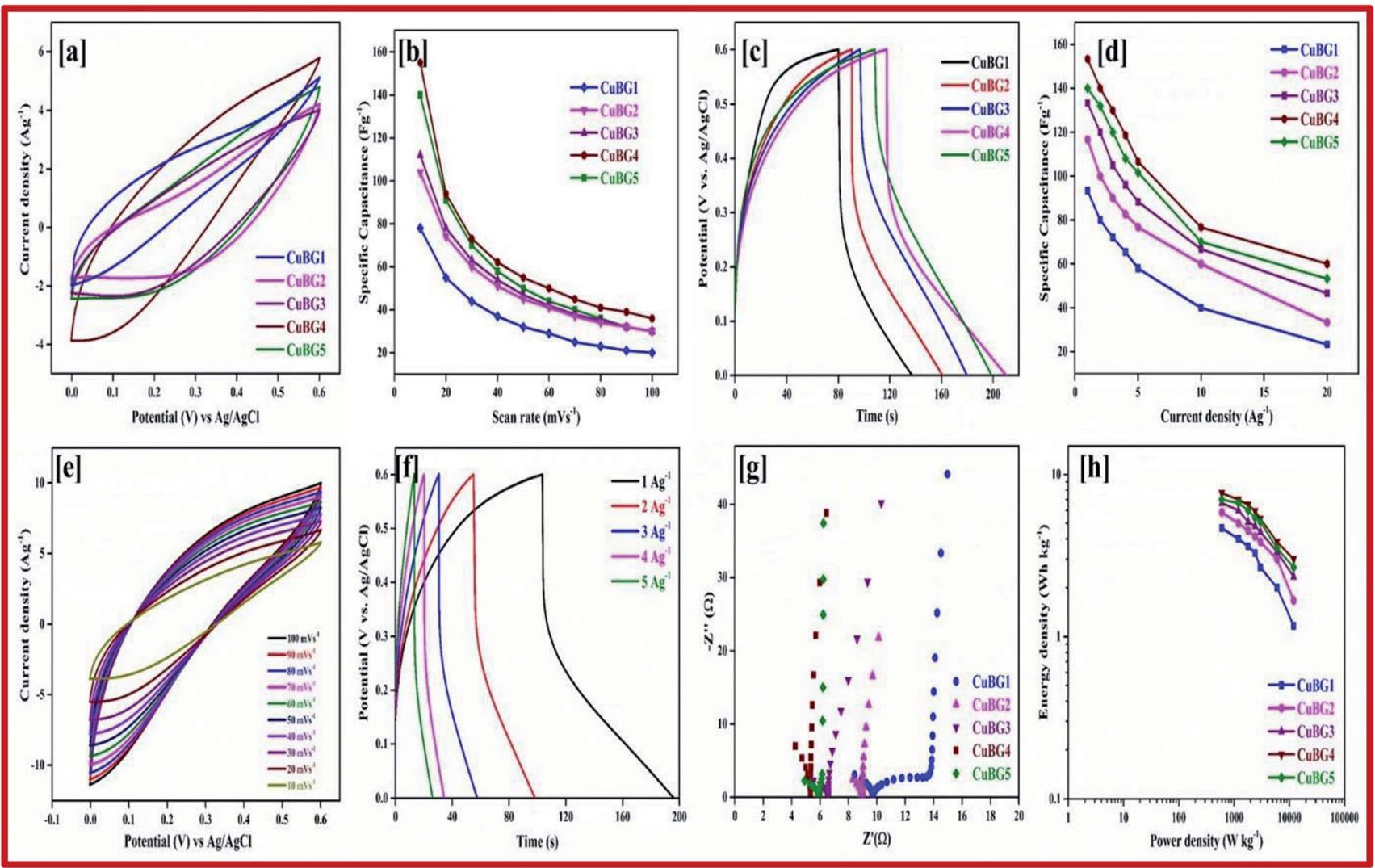

Fig. 9 (a) CV of all CuBG samples at a scan rate of $10 \mathrm{mV} \mathrm{s}^{-1}$. (b) Variation of the specific capacitance of CuBG samples at different scan rates. (c) Charge/discharge curve of CuBG samples at $1 \mathrm{Ag}^{-1}$. (d) Specific capacitance of samples at different current densities from 1 to $20 \mathrm{Ag}^{-1}$. (e) $\mathrm{CV}$ of CuBG4 at different scan rates from 100 to $10 \mathrm{mV} \mathrm{s}^{-1}$. (f) Charge/discharge curve for CuBG4 at different current densities from 1 to $20 \mathrm{Ag}{ }^{-1}$. (g) EIS-Nyquist plot for all of the CuBG samples. (h) Energy and power density of all samples calculated from the discharge time at different current densities in the $\mathrm{KOH}$ electrolyte.

\section{Electrochemical performance of CuBG electrode in $\mathrm{KOH}$}

Positive electrode material. Cyclic voltammetry, GCD and EIS were carried out to evaluate the electrochemical performance of the electrode materials. To obtain a higher capacitance, $6 \mathrm{M} \mathrm{KOH}$ was used as the electrolyte. The entire work was carried out in the three-electrode system as mentioned above.

The difference between the faradic and non-faradic reactions was estimated using CV. Fig. 9a presents the CV curves for CuBG1, CuBG2, CuBG3, CuBG4 and CuBG5 in a positive potential range of $0-0.6 \mathrm{~V}(\mathrm{vs} . \mathrm{Ag} / \mathrm{AgCl})$ at a similar scan rate of $10 \mathrm{mV} \mathrm{s}^{-1}$. All of the CV curves reveal EDLC behavior. Fig. S11 shows the $\mathrm{CV}$ and charge discharge curves for CuBG1, CuBG2, CuBG3 and CuBG5. The specific capacitance was calculated from the CV curve and is presented in Fig. $9 \mathrm{~b}$ for all of samples at different scan rates, and shows the gradual decrease in the capacitance and the increase in the scan rate without showing any sudden disturbance in the capacitance.

The areas of the curves are in the order CuBG4 > CuBG5 > CuBG3 > CuBG2 > CuBG1, that is, copper anchored onto a boron doped graphene nanosheet at a temperature of $850{ }^{\circ} \mathrm{C}$ has a high area value, which was further confirmed by GCD. Fig. 9e shows the CV curve of CuBG4 at various scan rates of $100-10 \mathrm{mV} \mathrm{s}^{-1}$ in the range of $0-0.6 \mathrm{~V}$.
Owing to the high electrolyte concentration no sharp anodic and cathodic peak appears in the electrode materials. In the three electrode system, the galvanostatic charge/discharge was performed in a potential range of $0-0.6 \mathrm{~V}$ at a current density between 1 to $20 \mathrm{Ag}^{-1}$.

The pseudocapacitive behavior of the electrode materials are indicated by the contribution of the double layer. Fig. 9c shows the charge/discharge for all of the samples at $1 \mathrm{Ag}^{-1}$, from the discharge curve the capacitance was calculated, which confirms CuBG4 $\left(153 \mathrm{Fg}^{-1}\right)$ is higher than the other materials CuBG5 (140 $\left.\mathrm{Fg}^{-1}\right)>\operatorname{CuBG} 3\left(133 \mathrm{~F} \mathrm{~g}^{-1}\right)>$ CuBG2 $\left(116 \mathrm{Fg}^{-1}\right)>$ CuBG1 $(93 \mathrm{~F}$ $\left.\mathrm{g}^{-1}\right)$. The specific capacitance of all of the samples at different current densities 1 to $20 \mathrm{Ag}^{-1}$ are given in Fig. 9d, which proves that even at high current densities the capacitance is retained at

Table 2 Electrochemical parameters for the EIS-Nyquist plot in $\mathrm{KOH}$

\begin{tabular}{lllllll}
\hline Sample & $R_{\mathrm{s}}(\Omega)$ & $R_{\mathrm{ct} 1}(\Omega)$ & $R_{\mathrm{ct} 2}(\Omega)$ & $C_{\mu}(\mathrm{F})$ & $W_{\mathrm{s}}$ & $\chi^{2}$ \\
\hline CuBG1 & 1.748 & 9.434 & 36.75 & 0.186 & 0.4398 & $8.62 \times 10^{-4}$ \\
CuBG2 & 1.752 & 6.934 & 29.68 & 0.305 & 0.1009 & $1.21 \times 10^{-4}$ \\
fCuBG3 & 1.0001 & 4.313 & 20.53 & 0.261 & 0.1857 & $4.53 \times 10^{-4}$ \\
CuBG4 & 0.2266 & 1.801 & 48.97 & 0.861 & 0.0459 & $2.16 \times 10^{-6}$ \\
CuBG5 & 0.3023 & 2.927 & 15.19 & 0.145 & 0.0277 & $1.52 \times 10^{-6}$
\end{tabular}


$40 \%$ without loss of distortion in the shape of the charge/ discharge.

The EIS of all of the samples are given in Fig. 9g, which shows a small semi-circle which intercepts at the real axis with a small resistance of less than 2 at higher frequency, and a steep increase of almost $90^{\circ}$ in a low frequency region, implying a high ionic conductivity between the electrode materials and the electrolyte interfaces. From the spectra it can be seen that CuBG4 has a very small resistance $\left(R_{\mathrm{ct}}\right)$ compared with the other materials. Thus, CuBG4 shows a high conductivity compared to the others in the KOH electrolyte as well shown in Table 2.

The performance of the individual materials was reported by the energy and power density in the Ragone plot, this was calculated by using the specific capacitance at different current densities, as given in Fig. 9h. Compared to the other samples, CuBG1 4.6 $\mathrm{W} \quad \mathrm{h} \mathrm{kg}{ }^{-1}$, CuBG2 $5.8 \mathrm{~W} \mathrm{~h} \mathrm{~kg}^{-1}$, CuBG3 $6.66 \mathrm{~W} \mathrm{~h} \mathrm{~kg}^{-1}$, and CuBG5 $7 \mathrm{~W} \mathrm{~h} \mathrm{~kg}^{-1}$, CuBG4 exhibits a higher energy density of $7.66 \mathrm{~W} \mathrm{~h} \mathrm{~kg}^{-1}$ at $600 \mathrm{~W} \mathrm{~kg}^{-1}$ which is in the supercapacitor region.

Negative electrode material. For the ASSC with the KOH/PVA gel electrolyte, activated carbon was used as the cathode (negative) electrode material. The activated carbon performance was evaluated using the three-electrode system. Fig. S12a $\dagger$ shows the $\mathrm{CV}$ of the activated carbon at different scan rates from 100 to $10 \mathrm{mV} \mathrm{s}^{-1}$ in the potential range of -1 to $0 \mathrm{~V}$. The rectangular shape of the CV curve shows the characteristics of EDLC in charge storage. Using the integrated value from the curve in eqn (1) the capacitance of the materials was calculated. Activated carbon shows $72 \mathrm{Fg}^{-1}$ at a scan rate of $10 \mathrm{mV} \mathrm{s}^{-1}$, as we increase the scan rate from 10 to $100 \mathrm{mV} \mathrm{s}^{-1}$, there was a gradual decrease in the specific capacitance owing to the fast movement of the ions on the surface itself, without the passage of ions into the electrode material.

Fig. S12b $\uparrow$ shows the charge/discharge of $\mathrm{AC}$ at the different current densities of $1,2,3,4,5,10$ and $20 \mathrm{Ag}^{-1}$. From the discharge time, the specific capacitance was calculated using eqn (2). Fig. S12c $\dagger$ shows the specific capacitance of AC at different current densities.

Asymmetric supercapacitor of CuBG4 in KOH/PVA. For the fabricated ASSC device of CuBG4//AC, the AC was used as a negative electrode and CuBG4 was used as a positive electrode in $\mathrm{KOH} / \mathrm{PVA}$ gel electrolyte. The electrochemical properties of the electrodes were first estimated via $\mathrm{CV}$ in a three-electrode system with $\mathrm{Pt}$ as the counter electrode and $\mathrm{Ag} / \mathrm{AgCl}$ as the reference electrode. The stable potential window of activated carbon between -1 to $0 \mathrm{~V}$ and CuBG between $0-0.6 \mathrm{~V}$ in the positive region were obtained. The sum of the potential range of the activated carbon $(1 \mathrm{~V})$ and $\mathrm{CuBG}(0.6 \mathrm{~V})$ was extended up to $1.6 \mathrm{~V}$ in the $\mathrm{KOH} / \mathrm{PVA}$ electrolyte solution for the ASSC of $\mathrm{CuBG} / /$ AC (Fig. 10b). It is necessary to balance the charges in the positive and negative electrodes as mentioned above in eqn (8), the mass of each electrode was balanced to fabricate the ASSC device of $\mathrm{CuBG} / / \mathrm{AC}$. Accordingly, the overall electrochemical performance was investigated in the $0-1.6 \mathrm{~V}$ potential window.

Fig. 10c shows the CV curve of the ASSC device at different potential window ranges from $0.8-1.6 \mathrm{~V}$ at a scan rate of $50 \mathrm{mV} \mathrm{s}^{-1}$, which shows a regular increase in the EDLC behavior with a distorted rectangular shape owing to the contribution of the faradic positive electrodes. At a high potential of 1.4-1.6 $\mathrm{V}$ a very small redox peak was observed owing to the insertion and extraction of the ions into the electrode materials during the oxidation and reduction process. However, as the potential increases to more than $1.7 \mathrm{~V}$, decomposition of electrolyte is evident with the evolution of oxygen/hydrogen, which increases the current dramatically, whereas the stability of the material decreases.

The CV curves shown in Fig. 10f result in both regular EDLC and pseudocapacitive behaviors at a high potential window of $1.6 \mathrm{~V}$ with different scan rates (10 to $100 \mathrm{mV} \mathrm{s}^{-1}$ ). From eqn (1) the specific capacitance was calculated as $87 \mathrm{Fg}^{-1}$ at a scan rate of $10 \mathrm{mV} \mathrm{s}^{-1}$, which is higher than the activated carbon electrode. This is owing to the overall combination of the primary pseudocapacitance and the redox property of the copper and boron, and the EDLC behavior of the graphene sheet in the device. Additionally, it was observed that both the materials are stable at a higher potential. The specific capacitance increases with a decrease in the scan rate from 100 to $10 \mathrm{mV} \mathrm{s}^{-1}$, as the movement of ions is limited at high scan rate only on the outer active surface, resulting in low utilization of the electroactive materials.

The ASSC device was further evaluated using GCD at various current densities from 1 to $20 \mathrm{Ag}^{-1}$. Fig. 10d shows the chargedischarge curve of the ASSC device at different potential ranges from $0.8-1.6 \mathrm{~V}$ at a current density of $1 \mathrm{Ag}^{-1}$. This shows the regular increase in the discharge time(s). There is a non-linear curve in the charge-discharge curve at very low current densities owing to the redox reaction from the copper on the electrode materials and the results remain close to the CV curve. From the slope, the initial drop of voltages $(I R)$ in the discharge curve for the internal resistance in the active materials were determined at different current densities. Fig. 10g shows the charge-discharge curve of the ASSC device at $1.6 \mathrm{~V}$ at different current densities from 1 to $5 \mathrm{Ag}^{-1}$. From the discharge curve the capacitance was calculated and is given in Fig. 10h, this indicates the gradual decrease in the specific capacitance at higher current densities. Fig. 11a gives the specific capacitance at different current densities with different cell voltages from 0.8 to $1.6 \mathrm{~V}$.

The energy and power density of the materials was calculated using the eqn (3) and (4). Fig. 11b shows the energy and power density at various current densities, it is evident that CuBG4 has the highest energy density of $31.1 \mathrm{~W} \mathrm{~h} \mathrm{~kg}^{-1}$ and a power density of $800 \mathrm{~W} \mathrm{~kg}^{-1}$ at $1 \mathrm{Ag}^{-1}$ in a cell voltage of $1.6 \mathrm{~V}$. The cyclic stability test for CuBG//AC was carried out over 5000 cycle at 5 $\mathrm{Ag}^{-1}$, in the highest potential range of 0 to $1.6 \mathrm{~V}$. Fig. 11c, and shows the capacitance retention of the ASSC device at different cycle numbers. The ASSC device exhibits an excellent electrochemical stability with a deterioration of $15 \%$ of the specific capacitance from the initial capacitance after 5000 cycles. This is due to the inactive boron in the active materials on the $\mathrm{KOH} /$ PVA solid electrolyte, as it is active on the $\mathrm{H}_{2} \mathrm{SO}_{4} / \mathrm{PVA}$ electrolyte. Hence, the electroactive materials show a very high stability in the $\mathrm{H}_{2} \mathrm{SO}_{4} / \mathrm{PVA}$ electrolyte compared to the $\mathrm{KOH} / \mathrm{PVA}$ solid electrolyte.

The fundamental behavior of supercapacitor was examined using EIS analysis. Furthermore, the impedance of the ASSC 

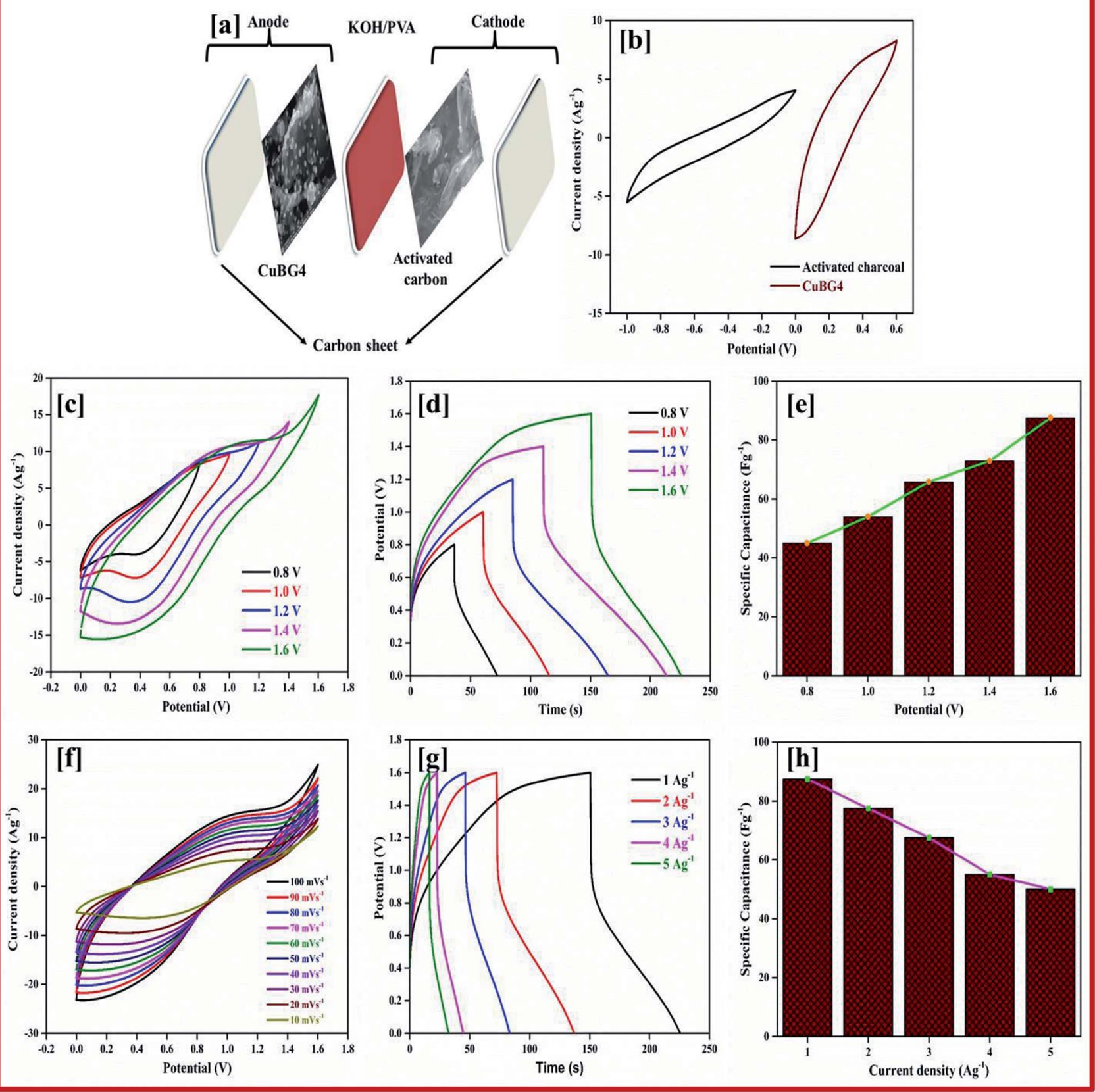

Fig. 10 (a) Schematic diagram of CuBG4. (b) CV of CuBG4//AC device at $50 \mathrm{mV} \mathrm{s}^{-1}$. (c) CV curve of CuBG4 at different potentials from 0.8 to 1.6 V. (d) Charge-discharge curve of CuBG4 at different potentials. (e) Specific capacitance of CuBG4 at different potential windows. (f and g) CV and charge-discharge curve of CuBG4 at different scan rates in a high potential of $1.6 \mathrm{~V}$; and (h) the specific capacitance of CuBG4 at different current densities from 1 to $5 \mathrm{Ag}^{-1}$ in a potential of $1.6 \mathrm{~V}$ in a KOH/PVA electrolyte.

device was measured after the $1^{\text {st }}$ and $5000^{\text {th }}$ cycle in the frequency range of $1 \mathrm{MHz}$ to $0.1 \mathrm{~Hz}$ at an open circuit potential with an AC perturbation of $2 \mathrm{mV}$. The obtained impedance is similar to an arc at a high frequency and a spike at a lower frequency, which demonstrates the long-term stability of this ASSC device. The impedance spectra were analyzed using the ZSimp win fitting method on the basis of an equivalent circuit and is shown in the inset of Fig. 11d. At a very high frequency, the combined resistance of the electrolyte and the ions and contact resistance of active materials $\left(R_{\mathrm{S}}\right)$ intercept at a real part $(Z)$. The $R_{\mathrm{s}}$ value is almost same for both of the spectra. The semicircle at a low frequency shows a major difference owing to faradic reaction and the double-layer on the surface, which corresponds to the charge-transfer resistance $\left(R_{\mathrm{ct}}\right)$. Owing to the Warburg resistance $\left(Z_{\mathrm{w}}\right)$ the slope of the curve was obtained, which is the ion diffusion to the electrode surface.

After 5000 cycles the charge-transfer resistance was increased from 0.8 to 6.8 owing to the corrosion caused by the dissolved oxygen in the electrolytes on the current collector during the charge-discharge cycle. Owing to the high concentration of electrolytes there was not a significant increase in the $R_{\text {ct }}$ value before and after 5000 cycles. 

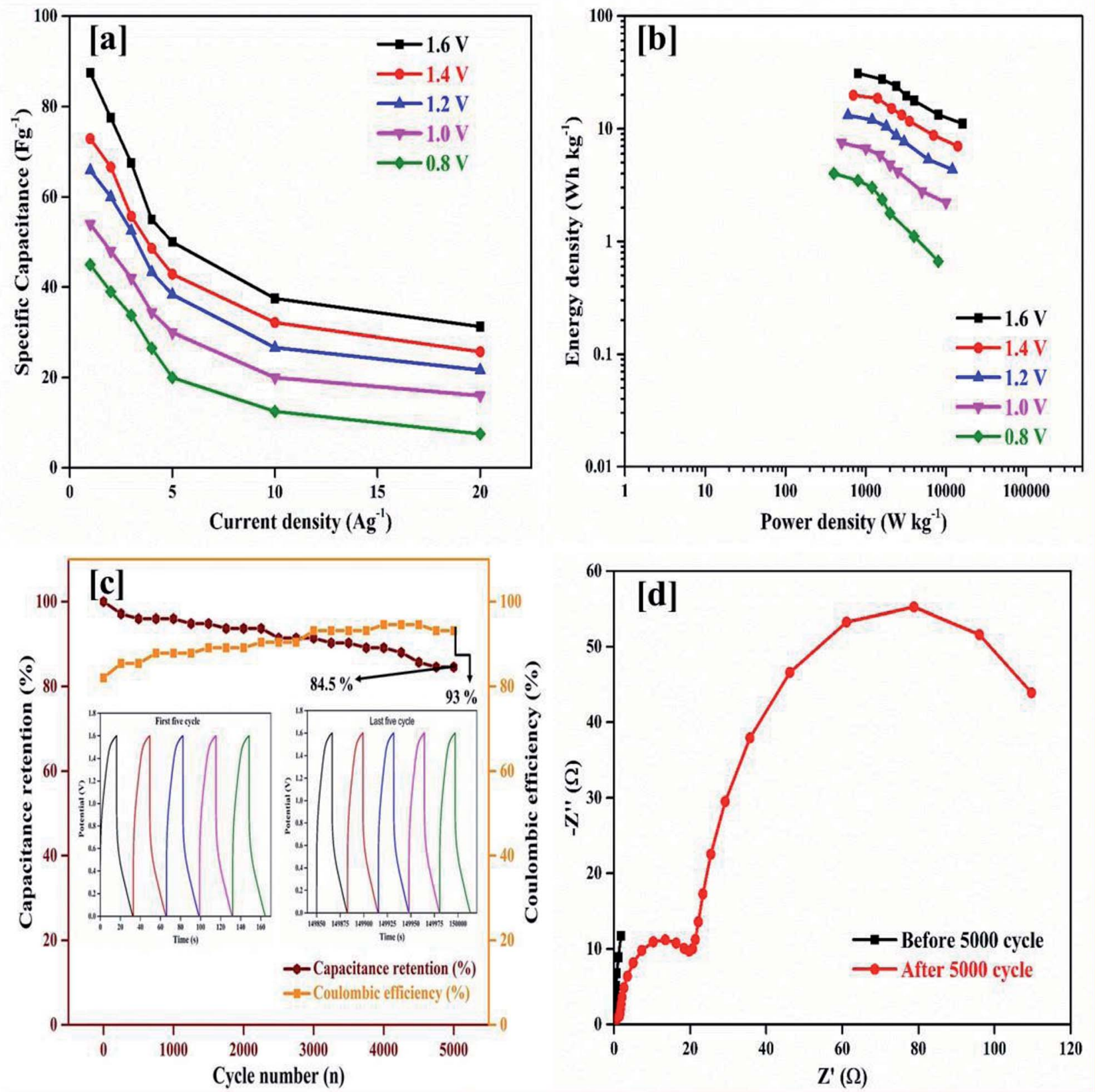

\begin{tabular}{|l|c|c|c|c|c|c|}
\hline Sample & $R_{s}(\Omega)$ & $R_{\mathrm{ct} 1}(\Omega)$ & $R_{\mathrm{ct} 2}(\Omega)$ & $C_{\mu}(F)$ & $W_{s}$ & $\chi^{2}$ \\
\hline Before & 0.01 & 0.865 & 14.3 & 0.1486 & 0.0678 & $3.18 \mathrm{E}-03$ \\
\hline After & 2.07 & 26.808 & 135.8 & 0.2148 & 0.1323 & $1.47 \mathrm{E}-02$ \\
\hline
\end{tabular}

Fig. 11 (a) Specific capacitance at different potentials and at different current densities from 1 to $20 \mathrm{Ag}^{-1}$ calculated from the discharge curve. (b) Energy and power density calculated from the specific capacitance at different potentials and different current densities. (c) Percentage of capacitance retention and percentage of coulombic efficiency for CuBG4//AC for 5000 cycles in a KOH/PVA electrolyte. (d) Nyquist plot before and after the cyclic stability test of 5000 cycles.

\section{Conclusion}

In this study, a novel and facile hydrothermal process, followed by a CVD method was utilized for the synthesis of copper anchored boron doped graphene nanoplatelets as active electrode materials. We designed a long-lasting and indestructible ASSC employing prepared electrode materials. In the solidstate symmetric supercapacitor CuBG4 shows a high capacitance of $483.3 \mathrm{Fg}^{-1}$ at a low current density of $1 \mathrm{Ag}^{-1}$ and demonstrated a high cyclic stability even at a current density of 
$5 \mathrm{Ag}^{-1}$, It also showed a capacitance retention of $91 \%$, even after 5000 cycles. The symmetric solid-state supercapacitor exhibits a high energy and power density at $1 \mathrm{Ag}^{-1}$. The novel ASSC device utilized rGO as the positive electrode and CuBG as the negative electrode with $\mathrm{H}_{2} \mathrm{SO}_{4}$ /PVA as the solid electrolyte, which was calibrated at a high potential window of $2.0 \mathrm{~V}$. At a current density of $1 \mathrm{Ag}^{-1}$ the device exhibits an eminent energy density of $132.5 \mathrm{~W} \mathrm{~h} \mathrm{~kg}^{-1}$ at a power density of $1000 \mathrm{~W}$ $\mathrm{kg}^{-1}$, respectively. The device exhibits an excellent cyclic stability, even after 5000 cycles with acapacitance retention of 90.8\%. We made a single asymmetric device utilizing the CuBG material as a positive electrode and activated carbon as the negative electrode material with $\mathrm{KOH} / \mathrm{PVA}$ as the solid electrolyte and tested green LEDs ( $2 \mathrm{~V}$ ) to determine the long life stability. The device showed a high energy density of $31.1 \mathrm{~W} \mathrm{~h} \mathrm{~kg}^{-1}$ at a power density of $800 \mathrm{~W} \mathrm{~kg}^{-1}$ in a potential window of $1.6 \mathrm{~V}$. At a current density of $5 \mathrm{Ag}^{-1}$ it shows a high cycle stability with an $84.5 \%$ capacitance retention and a $93 \%$ coulombic efficiency.

\section{Conflict of interest}

The authors declare no conflict of interest.

\section{Acknowledgements}

The authors are grateful to DST-FIST and UGC-DRS for providing the instrumentation facilities at the Department of Chemistry, Anna University, Chennai. The authors are also thankful to Dr K. Ashok Kumar and Mr N. S. Palani for their support in the discussion of the study materials.

\section{References}

1 A. Bora, K. Mohan, S. Doley and S. K. Dolui, ACS Appl. Mater. Interfaces, 2018, 10, 7996-8009.

2 J. Balamurugan, C. Li, S. G. Peera, N. H. Kim and J. H. Lee, Nanoscale, 2017, 9, 13747-13759.

3 N. S. Palani, N. S. Kavitha, K. S. Venkatesh, K. Ashok Kumar, V. Thirumal, A. Pandurangan, C. Sekar and R. Ilangovan, $J$. Solid State Electrochem., 2018, 22, 3273-3287.

4 V. Thirumal, A. Pandurangan, R. Jayavel and R. Ilangovan, Synth. Met., 2016, 220, 524-532.

5 R. Ragavan and A. Pandurangan, New J. Chem., 2017, 41, 11591-11599.

6 J. Balamurugan, C. Li, T. D. Thanh, O.-K. Park, N. H. Kim and J. H. Lee, J. Mater. Chem. A, 2017, 5, 19760-19772.

7 S. Park, H. Boo and T. D. Chung, Anal. Chim. Acta, 2006, 556, 46-57.

8 K. Wang, X. Dong, C. Zhao, X. Qian and Y. Xu, Electrochim. Acta, 2015, 152, 433-442.

9 G. Boopathi, G. G. Karthikeyan, S. M. Jaimohan, A. Pandurangan and A. L. F. de Barros, J. Phys. Chem. C, 2018, 122, 9257-9274.

10 W. Liu, X. Li, M. Zhu and X. He, J. Power Sources, 2015, 282, 179-186.
11 H. Wang, L.-F. Cui, Y. Yang, H. Sanchez Casalongue, J. T. Robinson, Y. Liang, Y. Cui and H. Dai, J. Am. Chem. Soc., 2010, 132, 13978-13980.

12 Y. Si and E. T. Samulski, Chem. Mater., 2008, 20, 6792-6797.

13 B. E. Conway, V. Birss and J. Wojtowicz, J. Power Sources, 1997, 66, 1-14.

14 J. Yan, Z. Fan, W. Sun, G. Ning, T. Wei, Q. Zhang, R. Zhang, L. Zhi and F. Wei, Adv. Funct. Mater., 2012, 22, 2632-2641.

15 R. A. Aziz, I. I. Misnon, K. F. Chong, M. M. Yusoff and R. Jose, Electrochim. Acta, 2013, 113, 141-148.

16 S. Stankovich, D. A. Dikin, G. H. B. Dommett, K. M. Kohlhaas, E. J. Zimney, E. A. Stach, R. D. Piner, S. T. Nguyen and R. S. Ruoff, Nature, 2006, 442, 282.

17 E. K. Athanassiou, R. N. Grass and W. J. Stark, Nanotechnology, 2006, 17, 1668.

18 A. Reina, X. Jia, J. Ho, D. Nezich, H. Son, V. Bulovic, M. S. Dresselhaus and J. Kong, Nano Lett., 2009, 9, 30-35.

19 J. Gunho, C. Minhyeok, C. Chu-Young, K. Jin Ho, P. Woojin, L. Sangchul, H. Woong-Ki, K. Tae-Wook, P. Seong-Ju, H. Byung Hee, K. Yung Ho and L. Takhee, Nanotechnology, 2010, 21, 175201.

20 M. F. El-Kady, V. Strong, S. Dubin and R. B. Kaner, Science, 2012, 335, 1326.

21 B. E. Conway and W. G. Pell, J. Solid State Electrochem., 2003, 7, 637-644.

22 Z. Yu, M. McInnis, J. Calderon, S. Seal, L. Zhai and J. Thomas, Nano Energy, 2015, 11, 611-620.

23 J. Balamurugan, T. T. Nguyen, V. Aravindan, N. H. Kim and J. H. Lee, Adv. Funct. Mater., 2018, 28, 1804663.

24 L. Niu, Z. Li, W. Hong, J. Sun, Z. Wang, L. Ma, J. Wang and S. Yang, Electrochim. Acta, 2013, 108, 666-673.

25 T. V. Khai, H. G. Na, D. S. Kwak, Y. J. Kwon, H. Ham, K. B. Shim and H. W. Kim, Chem. Eng. J., 2012, 211-212, 369-377.

26 Y. A. Kim, K. Fujisawa, H. Muramatsu, T. Hayashi, M. Endo, T. Fujimori, K. Kaneko, M. Terrones, J. Behrends, A. Eckmann, C. Casiraghi, K. S. Novoselov, R. Saito and M. S. Dresselhaus, ACS Nano, 2012, 6, 6293-6300.

27 M. Endo, C. Kim, T. Karaki, T. Tamaki, Y. Nishimura, M. J. Matthews, S. D. M. Brown and M. S. Dresselhaus, Phys. Rev. B, 1998, 58, 8991-8996.

28 D.-W. Wang, F. Li, Z.-G. Chen, G. Q. Lu and H.-M. Cheng, Chem. Mater., 2008, 20, 7195-7200.

29 K. Nanjundan Ashok and B. Jong-Beom, Nanotechnology, 2015, 26, 492001.

30 Y. Zhang, W. Dai, Y. Liu and B. Ma, RSC Adv., 2017, 7, 82508257.

31 E. Rodríguez and R. García, Fuel, 2012, 93, 288-297.

32 D. P. Dubal, O. Ayyad, V. Ruiz and P. Gómez-Romero, Chem. Soc. Rev., 2015, 44, 1777-1790.

33 H. Peng, J. Zhou, K. Sun, G. Ma, Z. Zhang, E. Feng and Z. Lei, ACS Sustainable Chem. Eng., 2017, 5, 5951-5963.

34 S. J. Zhu, J. Q. Jia, T. Wang, D. Zhao, J. Yang, F. Dong, Z. G. Shang and Y. X. Zhang, Chem. Commun., 2015, 51, 14840-14843.

35 X. Wang, C. Yan, J. Yan, A. Sumboja and P. S. Lee, Nano Energy, 2015, 11, 765-772. 
36 J. S. Shaikh, R. C. Pawar, R. S. Devan, Y. R. Ma, P. P. Salvi, S. S. Kolekar and P. S. Patil, Electrochim. Acta, 2011, 56, 2127-2134.

37 G. Wang, J. Huang, S. Chen, Y. Gao and D. Cao, J. Power Sources, 2011, 196, 5756-5760.

38 G. J. Navathe, D. S. Patil, P. R. Jadhav, D. V. Awale, A. M. Teli, S. C. Bhise, S. S. Kolekar, M. M. Karanjkar, J. H. Kim and P. S. Patil, J. Electroanal. Chem., 2015, 738, 170-175.

39 H. Z. Ibupoto, K. Khun, V. Beni, X. Liu and M. Willander, Sensors, 2013, 13, 7926-7938.

40 D. V. Awale, S. C. Bhise, S. K. Patil, M. M. Vadiyar, P. R. Jadhav, G. J. Navathe, J. H. Kim, P. S. Patil and S. S. Kolekar, Ceram. Int., 2016, 42, 2699-2705.

41 S. Wang, X. Huang, Y. He, H. Huang, Y. Wu, L. Hou, X. Liu, T. Yang, J. Zou and B. Huang, Carbon, 2012, 50, 2119-2125.

42 H. Li, W. Kang, B. Xi, Y. Yan, H. Bi, Y. Zhu and Y. Qian, Carbon, 2010, 48, 464-469.

43 C. Hao, F. Xiao and Z. Cui, J. Nanopart. Res., 2008, 10, 47-51. 44 B. Vidyadharan, I. I. Misnon, J. Ismail, M. M. Yusoff and R. Jose, J. Alloys Compd., 2015, 633, 22-30.

45 Y. Liu, H. Huang and X. Peng, Electrochim. Acta, 2013, 104, 289-294.

46 Y. Liu, Y. Ying, Y. Mao, L. Gu, Y. Wang and X. Peng, Nanoscale, 2013, 5, 9134-9140.

47 B. Zhao, P. Liu, H. Zhuang, Z. Jiao, T. Fang, W. Xu, B. Lu and Y. Jiang, Hierarchical self-assembly of microscale leaf-like CuO on graphene sheets for high-performance electrochemical capacitors, 2012.

48 Y. Luo, Q. e. Zhang, W. Hong, Z. Xiao and H. Bai, Phys. Chem. Chem. Phys., 2018, 20, 131-136.

49 J. Chen, B. Yao, C. Li and G. Shi, Carbon, 2013, 64, 225-229.

50 B. Zeng, X. Chen, X. Ning, C. Chen, W. Deng, Q. Huang and W. Zhong, Appl. Surf. Sci., 2013, 276, 482-486.

51 K. Krishnamoorthy and S.-J. Kim, Mater. Res. Bull., 2013, 48, 3136-3139.

52 J. Huang, Y. Zhu, X. Yang, W. Chen, Y. Zhou and C. Li, Flexible 3D Porous CuO Nanowire Arrays for Enzymeless Glucose Sensing: in situ Engineered versus ex situ Piled, 2015.
53 B. Li, T. Liu, L. Hu and Y. Wang, J. Phys. Chem. Solids, 2013, 74, 635-640.

54 D.-W. Kim, K.-Y. Rhee and S.-J. Park, J. Alloys Compd., 2012, 530, 6-10.

55 M. Yin, C.-K. Wu, Y. Lou, C. Burda, J. T. Koberstein, Y. Zhu and S. O'Brien, J. Am. Chem. Soc., 2005, 127, 9506-9511.

56 Y.-K. Hsu, C.-H. Yu, Y.-C. Chen and Y.-G. Lin, Electrochim. Acta, 2013, 105, 62-68.

57 L. Q. Lu and Y. Wang, J. Mater. Chem., 2011, 21, 1791617921.

58 Z. Peng, R. Ye, J. A. Mann, D. Zakhidov, Y. Li, P. R. Smalley, J. Lin and J. M. Tour, ACS Nano, 2015, 9, 5868-5875.

59 X. Dong, C.-Y. Su, W. Zhang, J. Zhao, Q. Ling, W. Huang, P. Chen and L.-J. Li, Phys. Chem. Chem. Phys., 2010, 12, 2164-2169.

60 M. Endo, T. Hayashi, S.-H. Hong, T. Enoki and M. S. Dresselhaus, J. Appl. Phys., 2001, 90, 5670-5674.

61 W. Cermignani, T. E. Paulson, C. Onneby and C. G. Pantano, Carbon, 1995, 33, 367-374.

62 L. Yang, S. Jiang, Y. Zhao, L. Zhu, S. Chen, X. Wang, Q. Wu, J. Ma, Y. Ma and Z. Hu, Angew. Chem., Int. Ed., 2011, 50, $7132-7135$.

63 X. Bo and L. Guo, Phys. Chem. Chem. Phys., 2013, 15, 24592465.

64 G. Panomsuwan, N. Saito and T. Ishizaki, Electrochem. Commun., 2015, 59, 81-85.

65 A. Pullamsetty, M. Subbiah and R. Sundara, Int. J. Hydrogen Energy, 2015, 40, 10251-10261.

66 A. K. Nayak, A. K. Das and D. Pradhan, ACS Sustainable Chem. Eng., 2017, 5, 10128-10138.

67 C. Dong, Y. Wang, J. Xu, G. Cheng, W. Yang, T. Kou, Z. Zhang and Y. Ding, 3D Binder-Free $\mathrm{Cu}_{2} \mathrm{O} @ \mathrm{Cu}$ Nanoneedle Arrays for High-Performance Asymmetric Supercapacitors, 2014.

68 J. Balamurugan, C. Li, V. Aravindan, N. H. Kim and J. H. Lee, Adv. Funct. Mater., 2018, 28, 1803287.

69 T. T. Nguyen, J. Balamurugan, N. H. Kim and J. H. Lee, J. Mater. Chem. A, 2018, 6, 8669-8681. 